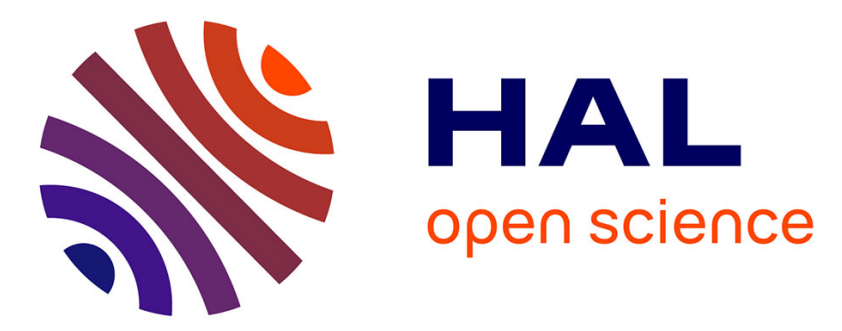

\title{
Synthesis and pharmacological evaluation of dual ligands for melatonin (MT1/MT2) and serotonin 5-HT2C receptor subtypes (II)
}

\author{
Mohamed Ettaoussi, Basile Peres, A Errazani, J.A. Boutin, Daniel-Henri
}

Caignard, Philippe Delagrange, Pascal Berthelot, Patricia Melnyk, Saïd Yous

\section{- To cite this version:}

Mohamed Ettaoussi, Basile Peres, A Errazani, J.A. Boutin, Daniel-Henri Caignard, et al.. Synthesis and pharmacological evaluation of dual ligands for melatonin (MT1/MT2) and serotonin 5-HT2C receptor subtypes (II). European Journal of Medicinal Chemistry, 2015, 90, pp.822-833. 10.1016/j.ejmech.2014.12.021 . hal-02060835

\section{HAL Id: hal-02060835 https://hal.science/hal-02060835}

Submitted on 8 Mar 2019

HAL is a multi-disciplinary open access archive for the deposit and dissemination of scientific research documents, whether they are published or not. The documents may come from teaching and research institutions in France or abroad, or from public or private research centers.
L'archive ouverte pluridisciplinaire HAL, est destinée au dépôt et à la diffusion de documents scientifiques de niveau recherche, publiés ou non, émanant des établissements d'enseignement et de recherche français ou étrangers, des laboratoires publics ou privés. 
European Journal of Medicinal Chemistry, 2015, 90, 822-33.

DOI : 10.1016/j.ejmech.2014.12.021

\section{Synthesis and pharmacological evaluation of dual ligands for melatonin (MT $1 \mathrm{MT}_{2}$ ) and serotonin $5-\mathrm{HT}_{2} \mathrm{C}$ receptor subtypes (II)}

Mohamed Ettaoussi, ${ }^{\mathrm{a}, \mathrm{b}, \perp, *}$ Basile Pérès, ${ }^{\mathrm{a}, \mathrm{b}, \perp}$ Aïcha Errazani, ${ }^{\mathrm{a}, \mathrm{b}}$ Jean A. Boutin, ${ }^{\mathrm{c}}$ Daniel-Henri Caignard, ${ }^{\mathrm{d}}$ Philippe Delagrange, ${ }^{\mathrm{d}}$ Patricia Melnyk, ${ }^{\mathrm{a}, \mathrm{b}}$ Pascal Berthelot ${ }^{\mathrm{a}, \mathrm{b}}$ and Saïd Yous ${ }^{\mathrm{a}, \mathrm{b}, *}$

${ }^{a}$ Université Lille Nord de France, F-59000 Lille, France

${ }^{b}$ UDSL, EA GRIIOT, UFR Pharmacie, F-59000 Lille, France

${ }^{c}$ Biotechnologies, Pharmacologie Moléculaire et Cellulaire, Institut de Recherches Servier, 78290 Croissy-sur-Seine, France

${ }^{d}$ Unité de Recherches et Découvertes en Neurosciences, Institut de Recherches Servier, 78290 Croissy-sur-Seine, France

${ }^{\perp}$ Both investigators equally contributed to this work

\section{Corresponding Author.}

*Phone: +1 438990 5912. Fax: +1 514398 5152. E-mail address: $\underline{\text { m.ettaoussi@yahoo.fr, }}$ 
said.yous@univ-lille2.fr

*Current Address of Dr. Ettaoussi: McGill University, Department of Psychiatry, Montreal QC-Canada.

\section{GRAPHICAL ABSTRACT}

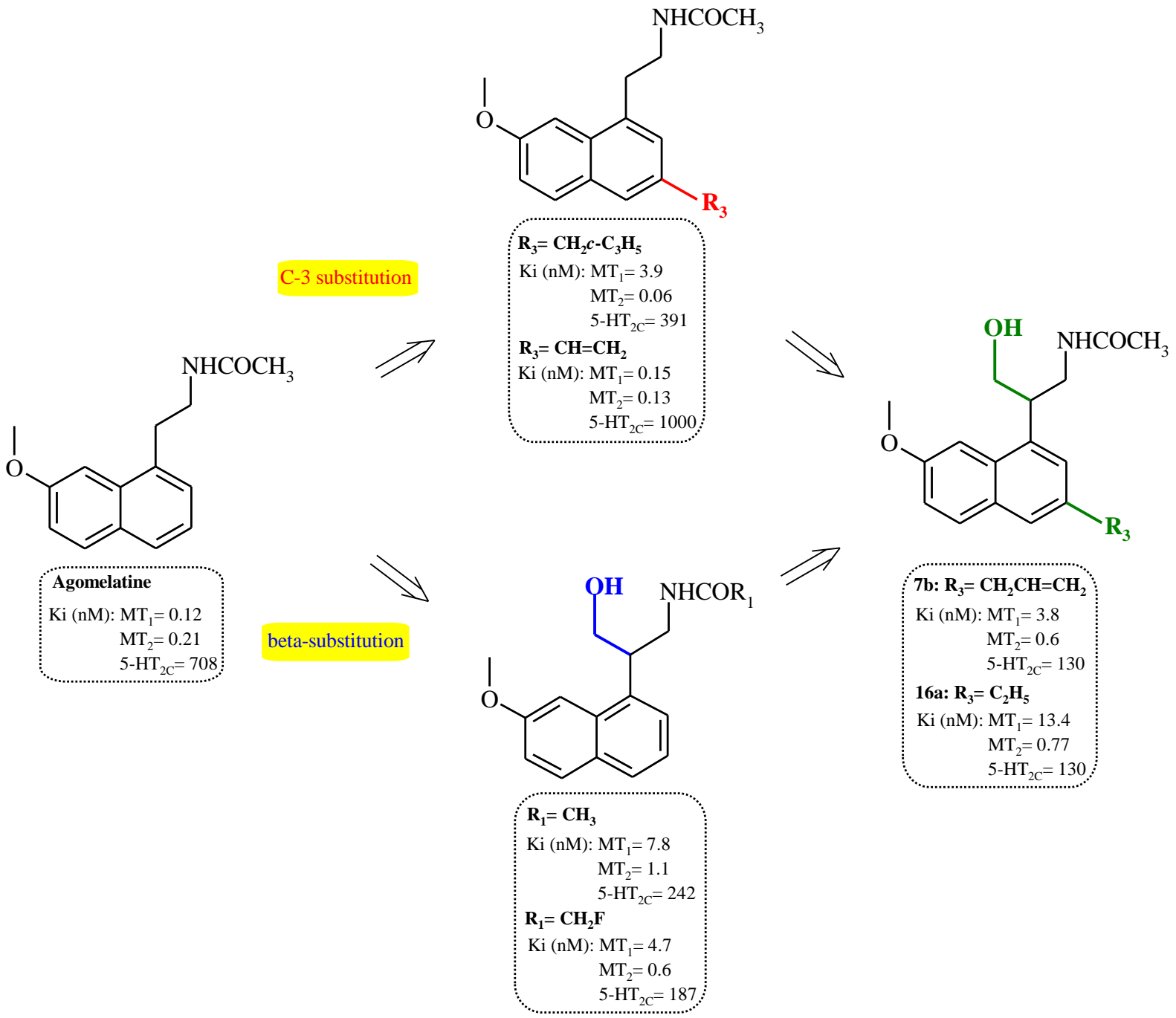

A new series of agomelatine analogues dual ligands for melatonin and serotonin were synthesized issued from combination of $\beta$ - and C-3 modulations. Synthesized series conserved submicromolar melatonin binding affinities. 


\title{
RESEARCH HIGHLIGHTS:
}

- New agomelatine analogues dual ligands for melatonin and serotonin were reported

- Combination of $\beta$ - and C-3 modulations led to the improvement of serotonin binding affinity

- Synthesized series conserved melatonin binding affinities; The allyl 7b and ethyl 16a represented the more interesting compounds of this series.

- Methyl thiourea $\mathbf{1 2 h}$ represent one of the highest $\mathrm{MT}_{2}$ selective derivative nowadays reported

\begin{abstract}
In the current paper we report the synthesis and biological results of new series of molecules issued from the investigation of agomelatine $\mathrm{C}-3$ and $\beta$-acetamide positions. Accordingly, the introduction of a hydroxymethyl in the $\beta$-acetamide position and aliphatic groups in $\mathrm{C}-3$ position produced a positive effect on both the melatonin $\left(\mathrm{MT}_{1}, \mathrm{MT}_{2}\right)$ and serotonin $\left(5-\mathrm{HT}_{2} \mathrm{C}\right)$ binding affinities. In particular, the allyl $\mathbf{7 b}$ and ethyl $\mathbf{1 6 a}$ represented the more interesting compounds of this series. The introduction of methyl cycloalkyl groups (compounds 12a, 13a) exhibited no change in both $\mathrm{MT}_{2}$ and $5-\mathrm{HT}_{2} \mathrm{C}$ binding affinities while a decrease of $\mathrm{MT}_{1}$ binding affinity occured leading to $\mathrm{MT}_{2}$ selectivity. Finally, the acetamide modulation has led to methyl thiourea $\mathbf{1 2 h}$, bearing one of the highest $\mathrm{MT}_{2}$ selectivity nowadays reported.
\end{abstract}

\section{Key words}

Agomelatine, Melatonin receptors, $\mathrm{MT}_{2}$-selectivity, Serotonin 5- $\mathrm{HT}_{2 \mathrm{C}}$ receptor. 


\section{Abbreviations used}

$\mathrm{MT}_{1}$, melatonin receptor subtype $1 ; \mathrm{MT}_{2}$, melatonin receptor subtype 2; 5-HT2 , serotonin receptor subtype $2 \mathrm{C} ;\left[{ }^{35} \mathrm{~S}\right] \mathrm{GTP} \gamma \mathrm{S},\left[{ }^{35} \mathrm{~S}\right]$ guanosine-5'-O-(3-thio-triphosphate).

\section{Introduction}

Melatonin or $\mathrm{N}$-acetyl-5-methoxytryptamine is mainly produced and secreted by the pineal gland during the period of darkness following a circadian rhythm [1]. This neurohormone is the endogenous ligand for $\mathrm{MT}_{1}$ and $\mathrm{MT}_{2}$, two receptors belonging to the family of G protein-coupled receptors (GPCRs) and primarily expressed in the central nervous system (CNS) [2] and widely distributed in other tissues [3,4]. Melatonin interacts also with a low binding affinity site called $\mathrm{MT}_{3}$ and characterized as the hamster homologue of the human enzyme quinone reductase 2 [5]. Once secreted, melatonin plays an important role in modulating various physiological processes upon activation of its binding sites [6-8]. Since its isolation, then characterization by Aaron Lerner in 1958 [9], melatonin was extensively studied during the $20^{\text {th }}$ century in order to clarify its physiological and behavioural implications. Over the years were discovered and proved its biological implications. However, since the development of ramelteon and agomelatine (Chart 1) the interest of the scientific community is growing up significantly and special attention has been paid for the design and synthesis of selective ligands. The elucidation of the exact role of the two melatonin receptor subtypes remains a real challenge but may provide great potential in the comprehension of their biological functions and the development of specific ligands.

Melatonin was demonstrated to be involved in the regulation and re-establishment of circadian rhythms and sleep promoting [10]. Moreover, it is also suggested to be involved in a variety of other physiopathological processes. In fact, experimental evidence suggests its implication in type 2 diabetes [11], in depression [12-14], cancer [15], in Alzheimer and Parkinson diseases [16-17]. Furthermore, other studies showed the involvment of this 
neurohormone in the modulation of immunity, cardiovascular responses and in blood pressure control [18].

Our research group started working, two decades ago, on the discovery of new tools for the study of the melatoninergic system. Hence, a multicomponent research program was initiated and consisted in the synthesis of new ligands selective or not for one or the other of the melatonin binding sites $\mathrm{MT}_{1}, \mathrm{MT}_{2}$ and $M T_{3}$. A substantial work was done in terms of SAR and many interesting ligands were discovered [19-22]. In one of the investigated areas, the aim was to design and synthesize new molecules with a similar receptoriel profil as agomelatine, a melatonin $\mathrm{MT}_{1} / \mathrm{MT}_{2}$ agonist and serotonin $5-\mathrm{HT}_{2 \mathrm{C}}$ antagonist. To hit this objective, we previousely described the synthesis of new analogues issued from the modulation of different sites of agomelatine $[23,24]$. Accordingly, the modulation of the C-3 position of the naphthalene ring [23] and the $\beta$-position of the amide side chain [24] have been shown to possess positive effects on binding affinities at both $\left(\mathrm{MT}_{1}, \mathrm{MT}_{2}\right)$ and $5-\mathrm{HT}_{2} \mathrm{C}$. In the current work, we describe the synthesis and pharmacological results of compounds issued from the combination of these two modulations of agomelatine using $\beta$ hydroxymethyl-agomelatine as a lead.

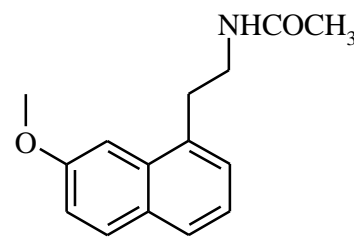

Agomelatine

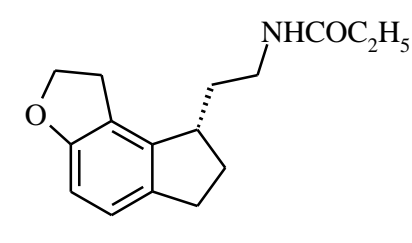

Ramelteon

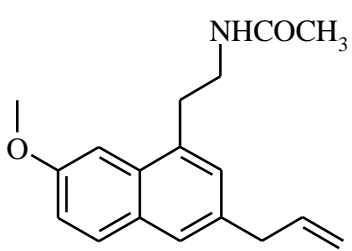

3-Allyl-agomelatine

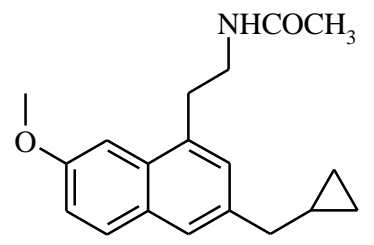

3-Methylcyclopropyl-agomelatine

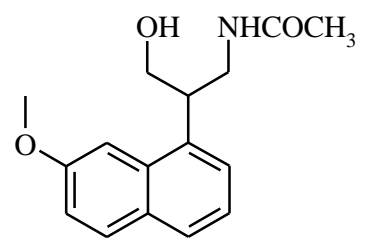

Beta-Hydroxymethyl-agomelatine

Chart 1. Melatonin and some of its analogues. 


\section{Results and Discussion}

2.1. Chemistry. Synthetic routes to the designed compounds are depicted in Schemes 1-4. The acetamide 4 was resynthesized from cyanoester 1 [24] through two synthetic routes (Scheme 1). First, by a catalytic hydrogenation over Raney nickel in acetic anhydride [25] leading to the desired amidoester $\mathbf{2 a}$ and two unsaturated isomers $(E, Z)-\mathbf{2} \mathbf{b}$. The treatment of compound 2a with a mixture of lithium aluminum hydride furnished the desired compound 4 in a global yield of 56\% [26]; The structures of isomers $E-\mathbf{2 b}$ and $Z-\mathbf{2 b}$ were determined by analytical studies using ${ }^{1} \mathrm{H},{ }^{13} \mathrm{C}$ and ROESY $1 \mathrm{D}$ NMR analyses. Z-2b identification was based on the presence of dipolar interactions between the ethylenic proton of the lateral chain and the naphthalenic proton $\mathrm{H}_{8}$ (see supporting information).

Scheme 1. Synthesis of compound 4<smiles>COC(=O)C(C#N)c1cccc2ccc(OC)cc12</smiles>

1

$\mathrm{c} \downarrow$<smiles>COc1ccc2cccc(C(CN)CO)c2c1</smiles>

3<smiles>COC(=O)C(=CNC(C)=O)c1cccc2ccc(OC)cc12</smiles>

b<smiles>COc1ccc2cccc(C(CO)CNC(C)=O)c2c1</smiles>

4

${ }^{a}$ Reagents: a) $\mathrm{Ac}_{2} \mathrm{O}, \mathrm{H}_{2}$, Ni-Raney, $60^{\circ} \mathrm{C}$; b) $\mathrm{LiAlH}_{4}, \mathrm{THF}, 0^{\circ} \mathrm{C}$; c) (i) $\mathrm{LiAlH}_{4}, \mathrm{AlCl}_{3}, \mathrm{Et}_{2} \mathrm{O}$, $0^{\circ} \mathrm{C}$ (ii) $\mathrm{HCl}_{\mathrm{g}}, \mathrm{Et}_{2} \mathrm{O}$; d) $\mathrm{K}_{2} \mathrm{CO}_{3}, \mathrm{EtOAc} / \mathrm{H}_{2} \mathrm{O}, \mathrm{CH}_{3} \mathrm{COCl}, 0^{\circ} \mathrm{C}-\mathrm{rt}$. 
The first strategy gave only access to acetamide derivative while the second method allowed preparation of different amides and areas as was previousely described by us [24]. This later method was realized in two steps, a one-pot reduction of nitrile and ester by treatment with a mixture of $\mathrm{LiAlH}_{4} / \mathrm{AlCl}_{3}$ followed by $\mathrm{N}$-acylation of the resulting primary amine into the desired acetamide 4 .

After preparation of lead compound 4, we moved to the synthesis of compounds issued from C-3 modulation. First, the access to vinyl and allyl derivatives $\mathbf{7 a}$ and $\mathbf{7 b}$ was achieved by $\mathrm{C}-3$ selective bromination of compound 4 in acetic acid at $70{ }^{\circ} \mathrm{C}$. The obtained ester 5 was then submitted to Stille cross-coupling reaction in the presence of vinyl and allyl tin derivatives to afford prodrugs $\mathbf{6 a}$ and $\mathbf{6 b}$ [27]. Finally, saponification of these later esters by sodium hydroxide in a hydro-alcoholic mixture furnished the desired compounds $\mathbf{7 a}$ and $\mathbf{7 b}$ in good yields (Scheme 2).

Scheme 2. Synthesis of compounds $7 \mathbf{a}-\mathbf{b}$ and $\mathbf{9}$

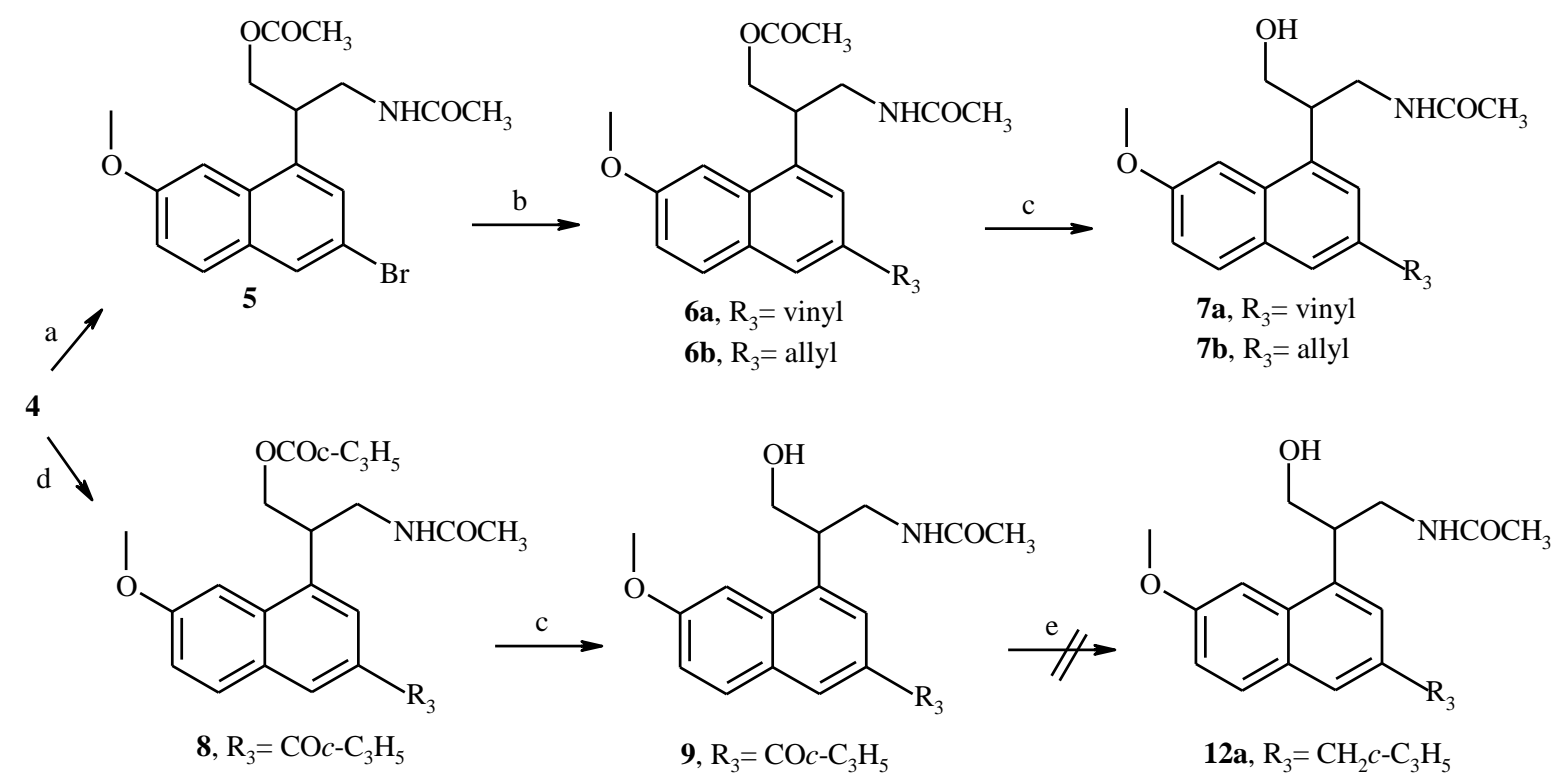

${ }^{a}$ Reagents: a) $\mathrm{Br}_{2}, \mathrm{AcOH}, 70^{\circ} \mathrm{C}$; b) $\mathrm{Pd}\left(\mathrm{PPh}_{3}\right)_{4}, \mathrm{Bu}_{3} \mathrm{SnR}_{3}$, toluene, $110^{\circ} \mathrm{C}$; c) $\mathrm{NaOH}_{(\mathrm{aq})}, \mathrm{MeOH}$; d) $\mathrm{H}_{5} \mathrm{C}_{3} c-\mathrm{COCl}, \mathrm{AlCl}_{3}, \mathrm{DCM}, 0^{\circ} \mathrm{C}$; e) $\mathrm{Et}_{3} \mathrm{SiH}, \mathrm{TFA}, \mathrm{rt}$. 
To prepare methylcyclopropyl 12a we have adopted a strategy based on direct acylation of compound 4 (Scheme 2). By using Friedel-Crafts acylation conditions and cyclopropanoyl chloride, we obtained the intermediate ester 8 in a low yield (15\%). Saponification of this later in methanol in the presence of sodium hydroxide furnished quantitatively acetamidoalcohol 9. Next, attempts to selectively reduce the ketone group onto methylene (compound 12a) using triethylsilane [28] were unsuccessful. This method figures out the difficulty of access to the desired compound by direct acylation of the amidolalcohol 4 . To overcome this synthetic difficulty, we developed a new strategy permiting also the access to different amides and ureas (12a-j and 13a-c) and depicted in Scheme 3. This strategy consists in direct acylation of cyanoester $\mathbf{1}$ under Friedel-crafts conditions followed by one-step reduction of nitrile, ketone and ester functions using a mixture of $\mathrm{LiAlH}_{4}$ and $\mathrm{AlCl}_{3}$ in dry diethyl ether. The formed primary amines $11 \mathrm{a}$ and $\mathbf{1 1 b}$ were then $N$-acylated following the Schotten-Baumann conditions to afford compounds 12a-d and 13a-b. Otherwise, fluoroacetamides 12e and 13c were prepared from amine bases 11a and 11b as previously described by us using ethyl fluoroacetate in 2,2,2-trifluoethanol. Finally, ureas and thioureas $(\mathbf{1 2 f}-\mathbf{j})$ were prepared from the amine hydrochloride 11a by treatment with the corresponding isocyanates or isothiocyanates [29]. 
Scheme 3. Synthesis of compounds 12a-j and 13a-c

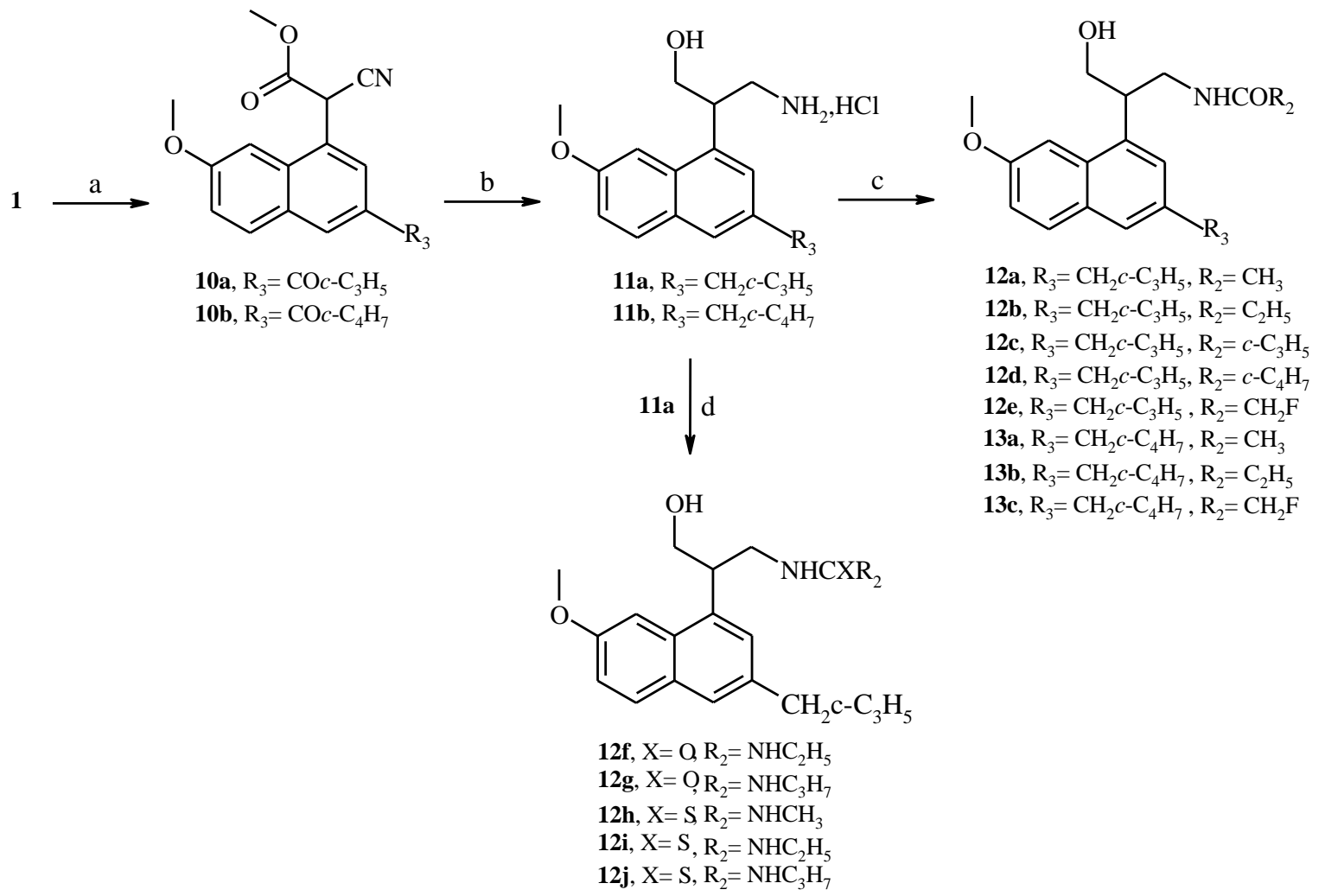

${ }^{a}$ Reagents: a) $\mathrm{R}_{3} \mathrm{Cl}, \mathrm{AlCl}_{3}, \mathrm{DCM}, 0^{\circ} \mathrm{C}$; b) (i) $\mathrm{LiAlH}_{4}, \mathrm{AlCl}_{3}, \mathrm{Et}_{2} \mathrm{O}, 0^{\circ} \mathrm{C}$, (ii) $\mathrm{HCl}_{(\mathrm{g})}, \mathrm{Et}_{2} \mathrm{O}$; c) $\mathrm{K}_{2} \mathrm{CO}_{3}$, EtOAc/ $\mathrm{H}_{2} \mathrm{O}$ then (i) $\mathrm{R}_{2} \mathrm{COCl}, 0^{\circ} \mathrm{C}$-rt for 12a-d, 13a-b, (ii) $\mathrm{FCH}_{2} \mathrm{CO}_{2} \mathrm{Et}$, TFE, reflux for 12e and 13c; d) $\mathrm{Et}_{3} \mathrm{~N}, \mathrm{R}_{2} \mathrm{CX}, \mathrm{DCM}, 0^{\circ} \mathrm{C}$.

Finally, C-3 alkylated derivatives (16a-16b) were prepared from intermediate 2a previously described in Scheme 1. Direct acylation of compound 2a in the presence of aluminum chloride and acetyl or propanoyl chloride provided intermediates 14a-b. Selective reduction of the ketone with triethylsilane in TFA furnished C-3 alkylated derivatives $\mathbf{1 5 a}-\mathbf{b}$. Finally, a selective chemical reduction of the methyl ester into hydroxymethyl using lithium aluminum hydride afforded the desired compounds $\mathbf{1 6 a}$ and $\mathbf{1 6 b}$ in good yields (Scheme 4). It is worth nothing that synthesis of compounds 16a-16b starting from compounds $\mathbf{1}$ and $\mathbf{4}$ was tried and abandoned because of low yields. 
Scheme 4. Synthesis of compounds 16a-16b<smiles>[R9]c1cc([C@@H](CNC(C)=O)C(=O)OC)c2cc(OC)ccc2c1C(CNC(C)=O)C(=O)OC</smiles>

${ }^{a}$ Reagents: a) $\mathrm{AlCl}_{3}$, DCM/DMF, $\mathrm{R}_{3} \mathrm{Cl}, 0^{\circ} \mathrm{C}$; b) $\mathrm{Et}_{3} \mathrm{SiH}$, TFA, rt; c) $\mathrm{LiAlH}_{4}, \mathrm{THF}, 0^{\circ} \mathrm{C}$.

Biological Results. Newly synthesized compounds were assayed at human $\mathrm{MT}_{1}$ and $\mathrm{MT}_{2}$ receptors stably transfected in Chinese Hamster Ovarian (CHO) cells, using 2$\left[{ }^{125} \mathrm{I}\right]$ iodomelatonin as radioligand [31]. Serotoninergic 5- $\mathrm{HT}_{2 \mathrm{C}}$ binding affinity was performed using Chinese Hamster Ovarian (CHO) cell lines stably expressing the human 5$\mathrm{HT}_{2 \mathrm{C}}$ receptors. Tables 1-3 report the chemical structures, melatonin $\left(\mathrm{MT}_{1}, \mathrm{MT}_{2}\right)$ and serotonin $5-\mathrm{HT}_{2 \mathrm{C}}$ binding affinities of these compounds.

As was previously stated, the introduction of a hydroxymethyl group in the $\beta$-position of the acetamide lateral chain and the modulation of C-3 position of agomelatine improved both the melatoninergic and serotoninergic 5- $\mathrm{HT}_{2 \mathrm{C}}$ binding affinities [23,24]. Hence, compound $\mathbf{4}$ was chosen as a lead for new modulations in order to prepare new "dual" ligands for melatonin and serotonin receptors. In the current study we report the synthesis and biological results of a new series of derivatives issued from C-3 position modulation of 4 . Accordingly, the introduction of aliphatic chains such as vinyl (7a), allyl (7b), ethyl (16a) and propyl (16b) showed in general a positive effect on serotoninergic 5-HT $2 \mathrm{C}$ binding affinity and the conservation of melatoninergic binding affinities (Tables 1-2). This observation was in agreement with our previous findings. In fact, the insertion of an allyl (7b) or an ethyl group (16a) produced an improvement of binding affinities at both melatonin $\left(\mathrm{MT}_{1}, \mathrm{MT}_{2}\right)$ and 
serotonin $5-\mathrm{HT}_{2 \mathrm{C}}$ receptor subtypes. These two compounds represented the more interesting ligands of this series. Besides, the vinyl 7a exhibited a good binding affinity at melatonin receptor subtypes but a lower binding affinity at 5- $\mathrm{HT}_{2 \mathrm{C}}$. On contrary, the propyl $\mathbf{1 6 b}$ showed the conservation of both serotonin 5- $\mathrm{HT}_{2 \mathrm{C}}$ and melatonin $\mathrm{MT}_{2}$ affinities with a decrease of the $\mathrm{MT}_{1}$ binding affinity.

Table 1. Binding affinities of compounds 4-7b

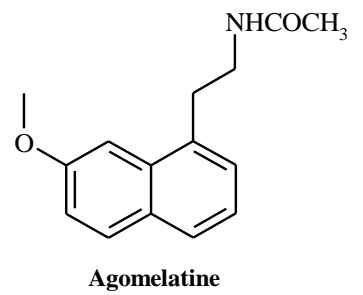<smiles>COCC(CNC(C)=O)c1cc(Br)cc2ccc(OC)cc12</smiles>

\begin{tabular}{|c|c|c|c|c|c|}
\hline Compound & $R_{I}$ & $R_{3}$ & $K_{i}(n M) M T_{1}[I 95](n)$ & $K_{i}(n M) M T_{2}[I 95](n)$ & $K_{i}(n M) 5-H T_{2}[I 95](n)$ \\
\hline Agomelatine & - & - & $0.12[0.12 ; 0.12](2)$ & $0.21[0.08 ; 0.57](2)$ & $708[674 ; 752](2)$ \\
\hline $\mathbf{4}$ & $\mathrm{H}$ & $\mathrm{H}$ & $7.8[7.2 ; 8.3](2)$ & $1.1[0.7 ; 1.5](2)$ & $242[164 ; 323](2)$ \\
\hline $\mathbf{5}$ & $\mathrm{COCH}_{3}$ & $\mathrm{Br}$ & $6.8[6.1 ; 7.7](2)$ & $0.74[0.72 ; 0.76](2)$ & $>10000(2)$ \\
\hline $\mathbf{6 b}$ & $\mathrm{COCH}_{3}$ & allyl & $33.0[25.3 ; 43.1](2)$ & $2.9[2.6 ; 3.4](2)$ & $>10000(2)$ \\
\hline $\mathbf{7 a}$ & $\mathrm{H}$ & vinyl & $6.6[5.9 ; 7.5](2)$ & $1.7[1.2 ; 2.4](2)$ & $1040[920 ; 1190](4)$ \\
\hline $\mathbf{7 b}$ & $\mathrm{H}$ & allyl & $3.8[2.6 ; 5.4](2)$ & $0.60[0.04 ; 1.0](2)$ & $130[90 ; 190](4)$ \\
\hline
\end{tabular}

$K i(\mathrm{nM})$ values are geometric mean values (with 95\% confidence limits shown in brackets) of at least $\mathrm{n}$ separate experiments performed in duplicate.

The introduction, in the C-3 position of naphthalene cycle, of a methyl cyclopropyl (12a) or a methyl cyclobutyl (13a), had no change in $\mathrm{MT}_{2}$ and $5-\mathrm{HT}_{2 \mathrm{C}}$ binding affinities in comparison with the parent ligand (Table 2). However, we noticed a decrease in the $\mathrm{MT}_{1}$ binding affinity resulting in an $\mathrm{MT}_{2}$ selectivity of about 79-fold for 12a and 19-fold for 13a, respectively. Otherwise, the acetamide functions of $\mathbf{1 2 a}$ and $\mathbf{1 3 a}$ were substituted with other amides (12b-12d and 13b-13c), fluoroacetamide (12e) or ureas and thioureas (12f-12j). The acetamide 12a replacement by a propylamide (12b) or a cyclopropylamide (12c) has 
produced a decrease of melatonin $\mathrm{MT}_{1}$ and serotonin 5- $\mathrm{HT}_{2 \mathrm{C}}$ binding affinities. In addition, the $\mathrm{MT}_{2}$ selectivity was fallen by 55 and 27-fold respectively in comparison with $\mathbf{1 2 a}$. Furthermore, the bulky cyclobutanamide 12d displayed a selectivity of 91-fold toward the $\mathrm{MT}_{2}$ receptor subtype while the fluoroacetamide $\mathbf{1 2 e}$ conserved the same good binding affinity towards $\mathrm{MT}_{2}$ and $5-\mathrm{HT}_{2 \mathrm{C}}$ receptors as the lead compound 4 and displayed a $\mathrm{MT}_{2}$ selectivity of about 153 -fold. 
Table 2. Binding affinities of compounds 9-16b

\begin{tabular}{|c|c|c|c|c|c|c|}
\hline Compd. & $\boldsymbol{R}_{2}$ & $R_{3}$ & $X$ & $\begin{array}{c}K_{i}(n M) M T_{1} \\
{[\text { [195](n) }}\end{array}$ & $\begin{array}{c}K_{i}(n M) M T_{2} \\
{[\text { [195](n) }}\end{array}$ & $\begin{array}{c}K_{i}(n M) 5-H T_{2 C} \\
{[195](n)}\end{array}$ \\
\hline 9 & $\mathrm{CH}_{3}$ & $\mathrm{CO} c-\mathrm{C}_{3} \mathrm{H}_{5}$ & $\mathrm{O}$ & $116[53 ; 254](2)$ & $81[61 ; 108](2)$ & $>10000(2)$ \\
\hline $12 a$ & $\mathrm{CH}_{3}$ & $\mathrm{CH}_{2} c-\mathrm{C}_{3} \mathrm{H}_{5}$ & $\mathrm{O}$ & $174[81 ; 376](3)$ & $2.2[1.3 ; 3.6](2)$ & $220[100 ; 500](2)$ \\
\hline $12 \mathrm{~b}$ & $\mathrm{C}_{2} \mathrm{H}_{5}$ & $\mathrm{CH}_{2} c-\mathrm{C}_{3} \mathrm{H}_{5}$ & $\mathrm{O}$ & $100[46 ; 215](3)$ & $1.8[1.4 ; 2.3](2)$ & $670[340 ; 1300](2)$ \\
\hline $12 \mathrm{c}$ & $c-\mathrm{C}_{3} \mathrm{H}_{5}$ & $\mathrm{CH}_{2} c-\mathrm{C}_{3} \mathrm{H}_{5}$ & $\mathrm{O}$ & $217[173 ; 273](2)$ & $8.1[4.6 ; 14](2)$ & $1060[1060 ; 1060](2)$ \\
\hline 12d & $c-\mathrm{C}_{4} \mathrm{H}_{7}$ & $\mathrm{CH}_{2} c-\mathrm{C}_{3} \mathrm{H}_{5}$ & $\mathrm{O}$ & $1040[724 ; 1490](2)$ & $11.4[6.3 ; 20.7](3)$ & $990[480 ; 2020](2)$ \\
\hline $12 \mathrm{e}$ & $\mathrm{CH}_{2} \mathrm{~F}$ & $\mathrm{CH}_{2} c-\mathrm{C}_{3} \mathrm{H}_{5}$ & $\mathrm{O}$ & $338[210 ; 544](2)$ & $2.2[2.0 ; 2.5](2)$ & $300[150 ; 620](3)$ \\
\hline $12 f$ & $\mathrm{NHC}_{2} \mathrm{H}_{5}$ & $\mathrm{CH}_{2} c-\mathrm{C}_{3} \mathrm{H}_{5}$ & $\mathrm{O}$ & $763[69 ; 84](2)$ & $15.9[13.7 ; 18.3](2)$ & $790[460 ; 1370](3)$ \\
\hline $12 \mathrm{~g}$ & $\mathrm{NHC}_{3} \mathrm{H}_{7}$ & $\mathrm{CH}_{2} c-\mathrm{C}_{3} \mathrm{H}_{5}$ & $\mathrm{O}$ & $2360(1)$ & $25.5[19.5 ; 33.2](2)$ & $990[440 ; 2250](2)$ \\
\hline $12 \mathrm{~h}$ & $\mathrm{NHCH}_{3}$ & $\mathrm{CH}_{2} c-\mathrm{C}_{3} \mathrm{H}_{5}$ & $S$ & $867[45 ; 169](2)$ & $0.48[39.6 ; 57.5](2)$ & $260[110 ; 610](3)$ \\
\hline $12 \mathrm{i}$ & $\mathrm{NHC}_{2} \mathrm{H}_{5}$ & $\mathrm{CH}_{2} c-\mathrm{C}_{3} \mathrm{H}_{5}$ & $S$ & $2800(1)$ & $70.5[51.5 ; 96.4](2)$ & $350[170 ; 750](3)$ \\
\hline $12 \mathrm{j}$ & $\mathrm{NHC}_{3} \mathrm{H}_{7}$ & $\mathrm{CH}_{2} c-\mathrm{C}_{3} \mathrm{H}_{5}$ & $S$ & $4870(1)$ & $143[69 ; 298](2)$ & $160[110 ; 230](2)$ \\
\hline 13a & $\mathrm{CH}_{3}$ & $\mathrm{CH}_{2} c-\mathrm{C}_{4} \mathrm{H}_{7}$ & $\mathrm{O}$ & $199[189 ; 209](2)$ & $10.2[6.1 ; 16.9](2)$ & $1110[520 ; 2250](2)$ \\
\hline $13 b$ & $\mathrm{C}_{2} \mathrm{H}_{5}$ & $\mathrm{CH}_{2} c-\mathrm{C}_{4} \mathrm{H}_{7}$ & $\mathrm{O}$ & $163[126 ; 211](2)$ & $0.81[0.65 ; 1.01](2)$ & $1000[670 ; 1480](2)$ \\
\hline $13 c$ & $\mathrm{CH}_{2} \mathrm{~F}$ & $\mathrm{CH}_{2} c-\mathrm{C}_{4} \mathrm{H}_{7}$ & $\mathrm{O}$ & $229[131 ; 398](2)$ & $>10000(2)$ & $580[390 ; 870](2)$ \\
\hline $16 a$ & $\mathrm{CH}_{3}$ & $\mathrm{C}_{2} \mathrm{H}_{5}$ & $\mathrm{O}$ & $13.4[5.8 ; 31.2](3)$ & $0.77[0.47 ; 1.29](2)$ & $130[120 ; 150](2)$ \\
\hline $16 \mathrm{~b}$ & $\mathrm{CH}_{3}$ & $\mathrm{C}_{3} \mathrm{H}_{7}$ & $\mathrm{O}$ & $59[31 ; 112](3)$ & $1.1[0.6 ; 2.0](2)$ & $210[160 ; 280](2)$ \\
\hline
\end{tabular}

$K i(\mathrm{nM})$ values are geometric mean values (with 95\% confidence limits shown in brackets) of at least $\mathrm{n}$ separate experiments performed in duplicate. 
With regard to the encouraging results obtained by the past with ureas and thioureas, the acetamide was then substituted by ureas $(\mathbf{1 2 f}-\mathbf{1 2 g})$ and thioureas $(\mathbf{1 2 h}-\mathbf{1 2 j})$. Hence, this modulation has led to a decrease of melatonin and serotonin $5-\mathrm{HT}_{2 \mathrm{C}}$ binding affinities (Table 2). The same effect was observed with thioureas but the methyl thiourea $\mathbf{1 2 h}$ who exhibited one of the highest $\mathrm{MT}_{2}$ selectivity nowadays reported. Furthermore, propyl thiourea $\mathbf{1 2} \mathbf{j}$ displayed one of the good serotonin $5-\mathrm{HT}_{2 \mathrm{C}}$ binding affinities of this series. Finally, the acetamide function of compound 13a was also submitted to modulation. Even its replacement by a propylamide (13b) had shown no noticed evolution, its substitution with a fluoroacetamide (13c) produced a lost of the $\mathrm{MT}_{2}$ affinity and a decrease of both $\mathrm{MT}_{1}$ and 5$\mathrm{HT}_{2 \mathrm{C}}$ binding affinities. 
Table 3. Functional activities of synthesized compounds

\begin{tabular}{|c|c|c|c|c|}
\hline \multirow[t]{2}{*}{ Compound } & \multicolumn{2}{|c|}{$h-M T_{l}$} & \multicolumn{2}{|c|}{$h-M T_{2}$} \\
\hline & $E C_{50}(n M) I 95(n)$ & $E_{\max }(\%) \pm E S M(n)$ & $E C_{50}(n M)[195](n)$ & $E_{\max }(\%) \pm \operatorname{ESM}(n)$ \\
\hline Agomelatine & $\begin{array}{c}1.56 \\
{[1.12 ; 2.00](4)}\end{array}$ & $99 \pm 6(4)$ & $0.21[0.13 ; 0.30](3)$ & $91 \pm 7(3)$ \\
\hline 4 & $72[64 ; 81](2)$ & $69 \pm 5(2)$ & $144[100 ; 208](2)$ & $48 \pm 6(2)$ \\
\hline 5 & $>10000(2)$ & nd & $1.4[1.3 ; 1.5](2)$ & $17 \pm 3(2)$ \\
\hline $\mathbf{6 b}$ & $>10000(2)$ & nd & $>10000(2)$ & nd \\
\hline $7 \mathbf{a}$ & $63[43 ; 91](2)$ & $63 \pm 4(2)$ & $0.54[0.27 ; 1.1](2)$ & $98 \pm 1(2)$ \\
\hline $7 \mathbf{b}$ & $41[31 ; 55](2)$ & $69 \pm 6(2)$ & $0.53[0.45 ; 0.61](2)$ & $87 \pm 14(2)$ \\
\hline 9 & $216(1)$ & $36(1)$ & $>10000(2)$ & nd \\
\hline $12 \mathbf{a}$ & $1180[1070 ; 1300](2)$ & $75 \pm 10(2)$ & $7.6[7.5 ; 7.7](2)$ & $102 \pm 11(2)$ \\
\hline $12 b$ & $1260[999 ; 1590](2)$ & $56 \pm 10(2)$ & $4.7[4.5 ; 5.0](2)$ & $107 \pm 4(2)$ \\
\hline $12 \mathrm{c}$ & $>10000(2)$ & nd & $26[19 ; 36](2)$ & $93 \pm 12(2)$ \\
\hline 12d & nd & nd & $52[31 ; 89](2)$ & $86 \pm 0$ \\
\hline $12 \mathrm{e}$ & $>10000(4)$ & nd & $3.2[1.5 ; 6.7](2)$ & $94 \pm 8(2)$ \\
\hline $12 f$ & nd & nd & $21[16 ; 27](2)$ & $155 \pm 42(2)$ \\
\hline $12 \mathrm{~g}$ & nd & nd & $77[37 ; 161](2)$ & $98 \pm 6(2)$ \\
\hline 12h & nd & nd & $37[31 ; 45](2)$ & $55 \pm 2(2)$ \\
\hline $12 \mathbf{i}$ & nd & nd & $632[412 ; 971](2)$ & $51 \pm 11(2)$ \\
\hline 13a & nd & nd & $4.1[3.3 ; 5.0](3)$ & $116 \pm 7(3)$ \\
\hline 13b & $1340[1140 ; 1570](2)$ & $87 \pm 4(2)$ & $3.1[2.4 ; 4.1](3)$ & $129 \pm 6(3)$ \\
\hline 13c & nd & nd & $5.9[3.6 ; 9.7](3)$ & $126 \pm 8(3)$ \\
\hline $16 \mathbf{a}$ & $31[11 ; 94](2)$ & $46 \pm 12(2)$ & $0.89[0.60 ; 1.31](2)$ & $99 \pm 5(2)$ \\
\hline $16 b$ & $198[74 ; 532](3)$ & $34 \pm 3(3)$ & $0.85[0.36 ; 2.0](2)$ & $58 \pm 6(2)$ \\
\hline
\end{tabular}

nd: not determined.

$E C_{50}$ values are geometric mean values of (n) experiments.

Emax values are arithmetic mean \pm S.E.M.

Regarding the intrinsic activity, we investigated the $\mathrm{EC}_{50}$ and $\mathrm{E}_{\max }$ at melatonin $\mathrm{MT}_{1}$ and $\mathrm{MT}_{2}$ receptor subtypes of synthesized compounds. The obtained results are illustrated in 
Table 3 and revealed the obtention of compounds with different pharmacological profiles. In fact, several compounds showed a partial agonist activity profile at $\mathrm{MT}_{1}$ and $\mathrm{MT}_{2}$ receptors (compounds $7 \mathbf{b}, \mathbf{1 2 c}, \mathbf{1 2 d}, \mathbf{1 2 i}, \mathbf{1 2} \mathbf{j}$, and $\mathbf{1 6 b})$ while other compounds (7a, 12a, 12b, 12f, 13ac, and 16a) behaved as partial agonist at $\mathrm{MT}_{1}$ and full agonist at $\mathrm{MT}_{2}$ receptor subtype.

\section{Conclusions}

We report in this paper the design and synthesis of a series of agomelatine analogues. The current strategy issued from the modulation of agomelatine $\beta$-acetamide position and C-3 position of the naphthalene ring led to compounds with different pharmacological profiles. In fact, insertion of aliphatic chains produced a positive effect on serotonin 5- $\mathrm{HT}_{2 \mathrm{C}}$ binding affinity and the conservation of melatonin binding affinities. The allyl $\mathbf{7 b}$ and ethyl $\mathbf{1 6 a}$ exhibited the most interesting results of this series. However, the introduction of sterically hindered groups (methyl cycloalkyls) resulted in a decrease of $\mathrm{MT}_{1}$ binding affinity leading to an $\mathrm{MT}_{2}$ selectivity and confirming the findings previously obtained with $\mathrm{C}-3$ modulation. At melatonin receptors, all the synthesized compounds showed a partial agonist activity at $\mathrm{MT}_{1}$ and full or partial agonist activities at $\mathrm{MT}_{2}$.

\section{Experimental Section}

Chemistry: Melting points were determined on a Büchi SMP-20 capillary apparatus and are uncorrected. IR spectra were recorded on a Vector 22 Bruker spectrometer. ${ }^{1} \mathrm{H}$ and ${ }^{13} \mathrm{C}$ NMR spectra were recorded on an AC300 Bruker spectrometer. Chemical shifts are reported in ppm units (parts per million) relative to $\left(\mathrm{CH}_{3}\right)_{4} \mathrm{Si}$. Elemental analyses for new compounds were performed by CNRS Laboratories (Vernaison, France) and the obtained results were within $0.4 \%$ of the theoretical values. Compounds purities were verified with analytical HPLC method and established to be $>95 \%$. 


\section{Methyl 3-Acetylamino-2-(7-methoxy-naphthalen-1-yl) propanoate (2a).}

Compound 1 (4.0 g, $39.2 \mathrm{mmol})$ was dissolved in acetic anhydride (200 mL) and the mixture was hydrogenated over Raney Ni (4.0 g) under pressure (30 bars) at $60{ }^{\circ} \mathrm{C}$ for $3 \mathrm{~h}$. After filtration on celite, the solvent was concentrated and the residue was dissolved in water (100 $\mathrm{mL}$ ) then extracted with ethyl ether. The organic phase was washed with a solution of sodium hydrogenocarbonate $(1 \mathrm{M})$, dried over $\mathrm{MgSO}_{4}$, and evaporated under reduced pressure to give 2a as a white solid after recrystallization from isopropylic ether (70\% yield). Mp $118-120{ }^{\circ} \mathrm{C}$; MS (APCI, pos. $30 \mathrm{~V}) \mathrm{m} / z:[\mathrm{M}+\mathrm{H}]^{+}, 302.16 ;{ }^{1} \mathrm{H} \mathrm{NMR}\left(\mathrm{CDCl}_{3}\right): \delta 2.01(\mathrm{~s}, 3 \mathrm{H}), 3.50(\mathrm{~m}, 1 \mathrm{H})$, $3.75(\mathrm{~s}, 3 \mathrm{H}), 3.90(\mathrm{~m}, 1 \mathrm{H}), 4.05(\mathrm{~s}, 3 \mathrm{H}), 4.76(\mathrm{~m}, 1 \mathrm{H}), 6.05(\mathrm{br} \mathrm{s}, 1 \mathrm{H}), 7.13-7.34(\mathrm{~m}, 3 \mathrm{H})$, 7.66-7.82 (m, 3H); IR (neat, $\left.\mathrm{cm}^{-1}\right): 3285(\mathrm{NH}), 1731(\mathrm{C}=\mathrm{O}), 1655(\mathrm{C}=\mathrm{O})$.

\section{Methyl (Z/E) 3-Acetylamino-2-(7-methoxy-naphthalen-1-yl) acrylate (2b).}

After compound $\mathbf{2}$ recrystallisation, the filtrate was purified on a silica gel column eluted with a mixture acetone-cyclohexane (3:7) and gave the two isomers $Z$-2b and $E$-2b as white solids (8\% yield). Z-2b: Mp $154-156{ }^{\circ} \mathrm{C}$; MS (APCI, pos. $\left.30 \mathrm{~V}\right) \mathrm{m} / z:[\mathrm{M}+\mathrm{H}]^{+}, 300.14 ;{ }^{1} \mathrm{H} \mathrm{NMR}$ $\left(\mathrm{CDCl}_{3}\right): \delta 1.92(\mathrm{~s}, 3 \mathrm{H}), 3.73(\mathrm{~s}, 3 \mathrm{H}), 3.85(\mathrm{~s}, 3 \mathrm{H}), 6.91(\mathrm{~d}, 1 \mathrm{H}, J=2.0), 6.93(\mathrm{br} \mathrm{s}, 1 \mathrm{H}), 7.21$ $(\mathrm{dd}, 1 \mathrm{H}, J=2.0, J=8.9), 7.32(\mathrm{~m}, 1 \mathrm{H}), 7.42(\mathrm{~m}, 1 \mathrm{H}), 7.80(\mathrm{~d}, 1 \mathrm{H}, J=8.9), 7.86(\mathrm{~m}, 1 \mathrm{H}), 8.52$ $(\mathrm{d}, 1 \mathrm{H}, J=12.2) ;{ }^{13} \mathrm{C} \mathrm{NMR}\left(\mathrm{CDCl}_{3}\right): \delta 23.5,52.0,55.4,102.9,112.1,119.1,123.5,128.6$, 128.8, 128.9, 129.5, 130.2, 132.8, 134.2, 158.4, 167.6, 167.7; IR (neat, $\left.\mathrm{cm}^{-1}\right): 3286(\mathrm{NH})$, $1718(\mathrm{C}=\mathrm{O}), 1636(\mathrm{C}=\mathrm{O})$.

E-2b: Mp 161-163 ${ }^{\circ} \mathrm{C}$; MS (APCI, pos. $\left.30 \mathrm{~V}\right) \mathrm{m} / z:[\mathrm{M}+\mathrm{H}]^{+}, 300.14 ;{ }^{1} \mathrm{H}$ NMR $\left(\mathrm{CDCl}_{3}\right): \delta 1.91$ (s, 3H), $3.73(\mathrm{~s}, 3 \mathrm{H}), 3.88(\mathrm{~s}, 3 \mathrm{H}), 6.92(\mathrm{~d}, 1 \mathrm{H}, J=2.0), 7.21(\mathrm{dd}, 1 \mathrm{H}, J=2.0, J=8.9), 7.32$ $(\mathrm{m}, 1 \mathrm{H}), 7.44(\mathrm{~m}, 1 \mathrm{H}), 7.71(\mathrm{~d}, 1 \mathrm{H}, J=11.0), 7.80(\mathrm{~d}, 1 \mathrm{H}, J=8.9), 7.87(\mathrm{~m}, 1 \mathrm{H}), 10.83(\mathrm{~d}$, $1 \mathrm{H}, J=11.0) ;{ }^{13} \mathrm{C} \mathrm{NMR}\left(\mathrm{CDCl}_{3}\right): \delta 23.9,52.8,55.3,104.0,109.1,118.3,123.1,128.2,128.8$, 129.0, 129.9, 132.3, 134.3, 138.6, 157.8, 168.4, 169.8; IR (neat, $\left.\mathrm{cm}^{-1}\right): 3336(\mathrm{NH}), 1723$ $(\mathrm{C}=\mathrm{O}), 1683(\mathrm{C}=\mathrm{O})$. 


\section{3-Hydroxy-2-(7-methoxy-naphthalen-1-yl)propylamine hydrochloride (3).}

To a suspension of $\mathrm{LiAlH}_{4}(3.04 \mathrm{~g}, 80 \mathrm{mmol})$ in dry diethyl ether $(300 \mathrm{~mL})$ at $0{ }^{\circ} \mathrm{C}$, was added dropwise a solution of $\mathrm{AlCl}_{3}(10.6 \mathrm{~g}, 80 \mathrm{mmol})$ in dry diethyl ether $(200 \mathrm{~mL})$. After 10 mn under stirring, a solution of $\mathbf{1}(5.1 \mathrm{~g}, 20 \mathrm{mmol})$ in dry diethyl ether (200 mL) was added. The reaction mixture was stirred for additional $30 \mathrm{mn}$, and hydrolyzed with a solution of $\mathrm{NaOH}(10 \mathrm{~g}, 250 \mathrm{mmol})$. After filtration and evaporation of the filtrate, the residue was dissolved in water and extracted with dichloromethane. The organic phase was washed with water, dried over $\mathrm{MgSO}_{4}$, filtered and evaporated under reduced pressure. The oily residue was then treated with $\mathrm{HCl}$ gas and recrystallized from acetonitrile. White solid (65\% yield); Mp 164-166 ${ }^{\circ} \mathrm{C}$. MS (APCI, pos. $\left.30 \mathrm{~V}\right) \mathrm{m} / z:[\mathrm{M}+\mathrm{H}]^{+}, 232.14 ;{ }^{1} \mathrm{H}$ NMR (DMSO- $d_{6}$ ): $\delta 3.20$ (m, 1H), $3.41(\mathrm{~m}, 1 \mathrm{H}), 3.69-3.72(\mathrm{~m}, 2 \mathrm{H}), 3.92-4.02(\mathrm{~m}, 4 \mathrm{H}), 5.31$ (br s, 1H), $7.22(\mathrm{dd}, 1 \mathrm{H}, J$ $=2.0, J=9.1), 7.33(\mathrm{~m}, 1 \mathrm{H}), 7.46(\mathrm{~m}, 1 \mathrm{H}), 7.51(\mathrm{~d}, 1 \mathrm{H}, J=2.0), 7.68(\mathrm{~m}, 1 \mathrm{H}), 7.88(\mathrm{~d}, 1 \mathrm{H}, J$ = 9.1), 7.99 (br s, 3H); IR (neat, $\left.\mathrm{cm}^{-1}\right)$ : 3330-2800; Anal. $\left(\mathrm{C}_{14} \mathrm{H}_{18} \mathrm{ClNO}_{2}\right) \mathrm{C}, \mathrm{H}, \mathrm{N}$.

$N$-[3-Hydroxy-2-(7-methoxy-naphthalen-1-yl)propyl]acetamide (4). Route 1: Compound 2a $(6.02 \mathrm{~g}, 20 \mathrm{mmol})$ was dissolved in dry tetrahydrofuran $(65 \mathrm{~mL})$ and cooled at $0{ }^{\circ} \mathrm{C}$ in an ice-bath, then aluminum lithium hydride $(1 \mathrm{~g}, 26 \mathrm{mmol})$ was added portionwise. After $1 \mathrm{~h}$ stirring, the reaction mixture was hydrolyzed with $1 \mathrm{~mL}$ of water, $1 \mathrm{~mL}$ of an aqueous solution of $\mathrm{NaOH}(15 \%)$ and $3 \mathrm{~mL}$ of water. The mineral formed was filtered and the filtrate was washed, dried over $\mathrm{MgSO}_{4}$ and evaporated under reduced pressure to lead to a white solid after recrystallization from acetonitrile ( $80 \%$ yield).

Route 2. To a suspension of $\mathbf{3}(5.35 \mathrm{~g}, 20 \mathrm{mmol})$ in $100 \mathrm{~mL}$ of a mixture of $\mathrm{H}_{2} \mathrm{O} / \mathrm{AcOEt}(1: 1)$ was added potassium carbonate $(8.28 \mathrm{~g}, 60 \mathrm{mmol})$ and the reaction mixture was cooled to 0 ${ }^{\circ} \mathrm{C}$ in an ice-bath. Acetyl chloride $(1.85 \mathrm{~mL}, 26 \mathrm{mmol})$ was added and the mixture stirred for $15 \mathrm{mn}$. The two phases were separated and the organic layer was washed with a solution of $\mathrm{HCl}(1 \mathrm{M})$ and water, dried over $\mathrm{MgSO}_{4}$, filtered and evaporated under reduced pressure. The 
desired product was collected as a white solid after recrystallization from acetonitrile $(80 \%$ yield). Mp 136-138 ${ }^{\circ} \mathrm{C}$; MS (APCI, pos. $\left.30 \mathrm{~V}\right) \mathrm{m} / z:[\mathrm{M}+\mathrm{H}]^{+}, 274.16 ;{ }^{1} \mathrm{H}$ NMR (DMSO- $\left.d_{6}\right): \delta$ $1.76(\mathrm{~s}, 3 \mathrm{H}), 3.33-7.37(\mathrm{~m}, 2 \mathrm{H}), 3.65-3.85(\mathrm{~m}, 3 \mathrm{H}), 3.96(\mathrm{~s}, 3 \mathrm{H}), 4.73$ (br s, $1 \mathrm{H}), 7.17(\mathrm{dd}, 1 \mathrm{H}$, $J=2.0, J=9.1), 7.32(\mathrm{~m}, 1 \mathrm{H}), 7.46(\mathrm{~m}, 1 \mathrm{H}), 7.62(\mathrm{~d}, 1 \mathrm{H}, J=2.0), 7.71(\mathrm{~m}, 1 \mathrm{H}), 7.83(\mathrm{~d}, 1 \mathrm{H}$, $J=9.1), 7.96\left(\right.$ br s, 1H); IR (neat, $\left.\mathrm{cm}^{-1}\right): 3280(\mathrm{NH}), 3199(\mathrm{OH}), 1645(\mathrm{C}=\mathrm{O})$; Anal. $\left(\mathrm{C}_{16} \mathrm{H}_{19} \mathrm{NO}_{3}\right) \mathrm{C}, \mathrm{H}, \mathrm{N}$.

3-Acetylamino-2-(3-bromo-7-methoxy-naphthalen-1-yl)propyle acetate (5). To a heated solution of $4(2.73 \mathrm{~g}, 10 \mathrm{mmol})$ in glacial acetic acid $(40 \mathrm{~mL})$ at $70{ }^{\circ} \mathrm{C}$, was added dropwise dibromine $(0.55 \mathrm{~mL}, 11 \mathrm{mmol})$. The reaction mixture was stirred for $4 \mathrm{~h}$ at this temperature then poured into water $(80 \mathrm{~mL})$ and extracted twice with $100 \mathrm{~mL}$ of diethyl ether. The organic phase was washed with $\mathrm{NaHCO}_{3}(1 \mathrm{M})$ and water, dried over $\mathrm{MgSO}_{4}$, filtered and evaporated under reduced pressure to furnish the desired product as a white solid (60\% yield), after recrystallization from toluene. Mp 150-152 ${ }^{\circ} \mathrm{C} ;{ }^{1} \mathrm{H}$ NMR (DMSO- $\left.d_{6}\right): \delta 1.76(\mathrm{~s}, 3 \mathrm{H}), 1.96(\mathrm{~s}$, $3 \mathrm{H}), 3.28(\mathrm{~m}, 1 \mathrm{H}), 3.50(\mathrm{~m}, 1 \mathrm{H}), 3.88-4.10(\mathrm{~m}, 4 \mathrm{H}), 4.40-4.43(\mathrm{~m}, 2 \mathrm{H}), 7.24(\mathrm{dd}, 1 \mathrm{H}, J=2.0$, $J=9.1), 7.53(\mathrm{~d}, 1 \mathrm{H}, J=2.0), 7.69(\mathrm{~s}, 1 \mathrm{H}), 7.83(\mathrm{~d}, 1 \mathrm{H}, J=9.1), 8.04(\mathrm{~s}, 1 \mathrm{H}), 8.12($ br s, $1 \mathrm{H})$; IR (neat, $\left.\mathrm{cm}^{-1}\right)$ : $3395(\mathrm{NH}), 1718(\mathrm{C}=\mathrm{O}), 1673(\mathrm{C}=\mathrm{O})$; Anal. $\left(\mathrm{C}_{18} \mathrm{H}_{20} \mathrm{BrNO}_{4}\right) \mathrm{C}, \mathrm{H}, \mathrm{N}$.

3-Acetylamino-2-(7-methoxy-3-vinyl-naphthalen-1-yl)propyle acetate (6a). Compound 5 $(1.5 \mathrm{~g}, 3.8 \mathrm{mmol})$ and triphenylphosphine palladium tetrakis $(0.219 \mathrm{~g}, 0.19 \mathrm{mmol})$ were dissolved in $22 \mathrm{~mL}$ of dry toluene under argon atmosphere, then vinyltributyltin $(5.7 \mathrm{mmol})$ was added dropwise cautiously and the mixture was refluxed for $2 \mathrm{~h}$. After cooling, the mixture was poured into $50 \mathrm{~mL}$ of an aqueous solution of $\mathrm{KF} 10 \%$ and the solid formed was filtered and washed with ethyl acetate. The organic phase was washed, dried over $\mathrm{MgSO}_{4}$ and evaporated under reduced pressure to give the desired product as a white solid after purification on silica gel column eluted with a mixture of ethyl acetate/cyclohexane $(8: 2)$. Recrystallized from toluene ( $30 \%$ yield); Mp 122-124 ${ }^{\circ} \mathrm{C}$; MS (APCI, pos. $30 \mathrm{~V}$ ) $\mathrm{m} / \mathrm{z}$ : 
$[\mathrm{M}+\mathrm{H}]^{+}, 342.19 ;{ }^{1} \mathrm{H}$ NMR (DMSO-d $): \delta 1.80(\mathrm{~s}, 3 \mathrm{H}), 1.97(\mathrm{~s}, 3 \mathrm{H}), 3.31(\mathrm{~m}, 1 \mathrm{H}), 3.54(\mathrm{~m}$, $1 \mathrm{H}), 3.79-4.10(\mathrm{~m}, 4 \mathrm{H}), 4.38(\mathrm{dd}, 1 \mathrm{H}, J=6.2, J=11.0), 4.52(\mathrm{dd}, 1 \mathrm{H}, J=7.2, J=11.0), 5.31$ $(\mathrm{d}, 1 \mathrm{H}, J=11.3), 5.95(\mathrm{~d}, 1 \mathrm{H}, J=17.6), 6.85(\mathrm{dd}, 1 \mathrm{H}, J=11.3, J=17.6), 7.16(\mathrm{dd}, 1 \mathrm{H}, J=$ 9.0, $J=2.4), 7.63(\mathrm{~m}, 1 \mathrm{H}), 7.68(\mathrm{~d}, 1 \mathrm{H}, J=2.4), 7.54(\mathrm{~m}, 1 \mathrm{H}), 7.77(\mathrm{~d}, 1 \mathrm{H}, J=9.0), 7.98(\mathrm{br}$ s, $1 \mathrm{H})$; IR (neat, $\left.\mathrm{cm}^{-1}\right): 3232(\mathrm{NH}), 1726(\mathrm{C}=\mathrm{O}), 1626(\mathrm{C}=\mathrm{O})$; Anal. $\left(\mathrm{C}_{20} \mathrm{H}_{23} \mathrm{NO}_{4}\right) \mathrm{C}, \mathrm{H}, \mathrm{N}$.

3-Acetylamino-2-(3-allyl-7-methoxy-naphthalen-1-yl)propyle acetate (6b).This compound was prepared from compound $\mathbf{5}$ and tributylvinyltin according to the procedure described above for 6a. The obtained compound was recrystallized from toluene; White solid (50\% yield); Mp 78-80 ${ }^{\circ} \mathrm{C}$; MS (APCI, pos. $\left.30 \mathrm{~V}\right) \mathrm{m} / z:[\mathrm{M}+\mathrm{H}]^{+}, 356.20 ;{ }^{1} \mathrm{H}$ NMR (DMSO- $\left.d_{6}\right): \delta$ $1.80(\mathrm{~s}, 3 \mathrm{H}), 1.97(\mathrm{~s}, 3 \mathrm{H}), 3.16(\mathrm{~m}, 1 \mathrm{H}), 3.40-3.65(\mathrm{~m}, 3 \mathrm{H}), 3.85-4.18(\mathrm{~m}, 4 \mathrm{H}), 4.38-3.42(\mathrm{~m}$, $2 \mathrm{H}), 5.10-5.15(\mathrm{~m}, 2 \mathrm{H}), 6.04(\mathrm{ddt}, 1 \mathrm{H}, J=6.8, J=10.0, J=17.1), 7.16(\mathrm{dd}, 1 \mathrm{H}, J=9.0, J=$ 2.4), $7.28(\mathrm{~m}, 1 \mathrm{H}), 7.53(\mathrm{~d}, 1 \mathrm{H}, J=2.4), 7.66(\mathrm{~m}, 1 \mathrm{H}), 7.78(\mathrm{~d}, 1 \mathrm{H}, J=9.0), 8.09$ (br s, $1 \mathrm{H})$; IR (neat, $\left.\mathrm{cm}^{-1}\right): 3238(\mathrm{NH}), 1725(\mathrm{C}=\mathrm{O}), 1633(\mathrm{C}=\mathrm{O})$; Anal. $\left(\mathrm{C}_{21} \mathrm{H}_{25} \mathrm{NO}_{4}\right) \mathrm{C}, \mathrm{H}, \mathrm{N}$.

$N$-[3-Hydroxy-2-(7-methoxy-3-vinyl-naphthalen-1-yl)propyl]acetamide $\quad$ (7a). $\quad$ To a solution of compound $\mathbf{6 a}(5.0 \mathrm{mmol})$ in methanol $(30 \mathrm{~mL})$ was added sodium hydroxide $(0.6$ $\mathrm{g}, 15.0 \mathrm{mmol}$ ) in solution $30 \mathrm{~mL}$ of water. The reaction mixture was heated at $50{ }^{\circ} \mathrm{C}$ for 30 minutes then acidified with an aqueous solution of $\mathrm{HCl}(1 \mathrm{M})$. The mixture was extracted twice with $30 \mathrm{~mL}$ of ethyl acetate and the organic phase was washed with water, dried over $\mathrm{MgSO}_{4}$ and evaporated under reduced pressure to give the desired product after recrystallization from acetonitrile as a white solid (80\% yield). mp 109-111 ${ }^{\circ} \mathrm{C}$; MS (APCI, pos. $30 \mathrm{~V}) \mathrm{m} / z:[\mathrm{M}+\mathrm{H}]^{+}, 300.18 ;{ }^{1} \mathrm{H}$ NMR (DMSO- $\left.d_{6}\right): \delta 1.80(\mathrm{~s}, 3 \mathrm{H}), 3.33-3.38(\mathrm{~m}, 2 \mathrm{H})$, 3.60-3.85 (m, 3H), $3.93(\mathrm{~s}, 3 \mathrm{H}), 4.56$ (br s, 1H), 5.32 (d, 1H, $J=11.3), 5.94$ (d, 1H, $J=17.6)$, $6.83(\mathrm{dd}, 1 \mathrm{H}, J=11.3, J=17.6), 7.16(\mathrm{dd}, 1 \mathrm{H}, J=9.0, J=2.4), 7.61(\mathrm{~m}, 1 \mathrm{H}), 7.68(\mathrm{~d}, 1 \mathrm{H}, J=$ 2.4), $7.55(\mathrm{~m}, 1 \mathrm{H}), 7.78(\mathrm{~d}, 1 \mathrm{H}, J=9.0), 7.98($ br s, $1 \mathrm{H}) ;{ }^{13} \mathrm{C} \mathrm{NMR}\left(\mathrm{CDCl}_{3}\right): \delta 23.1,41.6$, 
$42.3,55.7,63.1,103.1,113.9,118.5,122.1,125.2,129.4,130.8,132.3,133.7,137.1,137.5$, 158.0, 170.1; IR (neat, $\left.\mathrm{cm}^{-1}\right)$ : 3279, 3210, 1650; Anal. $\left(\mathrm{C}_{18} \mathrm{H}_{21} \mathrm{NO}_{3}\right) \mathrm{C}, \mathrm{H}, \mathrm{N}$.

$N$-[3-Hydroxy-2-(3-allyl-7-methoxy-naphthalen-1-yl)propyl]acetamide $\quad(7 \mathrm{~b}) . \quad$ This compound was prepared from compound $\mathbf{6 b}$ according to the procedure described for $\mathbf{7 a}$. Recrystallized from acetonitrile as a white solid (80\% yield); Mp 142-144 ${ }^{\circ} \mathrm{C}$; MS (APCI, pos. $30 \mathrm{~V}) \mathrm{m} / \mathrm{z}:[\mathrm{M}+\mathrm{H}]^{+}, 314.18 ;{ }^{1} \mathrm{H}$ NMR (DMSO- $\left.d_{6}\right): \delta 1.80(\mathrm{~s}, 3 \mathrm{H}), 3.38-3.44(\mathrm{~m}, 2 \mathrm{H})$, $3.50(\mathrm{~d}, 2 \mathrm{H}, J=6.7), 3.62-3.85(\mathrm{~m}, 3 \mathrm{H}), 3.93(\mathrm{~s}, 3 \mathrm{H}), 4.72(\mathrm{br} \mathrm{s}, 1 \mathrm{H}), 5.10-5.14(\mathrm{~m}, 2 \mathrm{H}), 6.03$ $(\mathrm{ddt}, 1 \mathrm{H}, J=6.7, J=10.0, J=17.1), 7.16(\mathrm{dd}, 1 \mathrm{H}, J=9.0, J=2.4), 7.32(\mathrm{~m}, 1 \mathrm{H}), 7.48(\mathrm{~d}$, $1 \mathrm{H}, J=2.4), 7.55(\mathrm{~m}, 1 \mathrm{H}), 7.77(\mathrm{~d}, 1 \mathrm{H}, J=9.0), 7.95(\mathrm{br} \mathrm{s}, 1 \mathrm{H}) ;{ }^{13} \mathrm{C} \mathrm{NMR}\left(\mathrm{CDCl}_{3}\right): \delta 23.1$, $40.1,41.6,42.2,55.6,63.1,102.8,116.3,118.2,125.4,126.2,129.6,130.2,132.3,134.7$, 136.9, 138.1, 157.5, 170.1; IR (neat, $\left.\mathrm{cm}^{-1}\right)$ : $3254(\mathrm{NH}), 3172(\mathrm{C}=\mathrm{O}), 1636(\mathrm{C}=\mathrm{O})$; Anal. $\left(\mathrm{C}_{19} \mathrm{H}_{23} \mathrm{NO}_{3}\right) \mathrm{C}, \mathrm{H}, \mathrm{N}$.

Preparation of compound 8. To a solution of compound $4(3.0 \mathrm{~g}, 11.0 \mathrm{mmol})$ in $50 \mathrm{~mL}$ of dry dichloromethane at $0{ }^{\circ} \mathrm{C}$, was added cautiously aluminum chloride $(8.8 \mathrm{~g}, 66.0 \mathrm{mmol})$ then cyclopropanoyle chloride $(3.3 \mathrm{~mL}, 36.4 \mathrm{mmol})$. The reaction mixture was stirred at room temperature for $1 \mathrm{~h}$, poured into water $(100 \mathrm{~mL})$ and the organic phase was washed with brine, dried over $\mathrm{MgSO}_{4}$ and evaporated under reduced pressure. The yellow oil obtained was then purified on a silica gel column eluted with a mixture of acetone-cyclohexane (3:7) to lead to compound $\mathbf{8}$.

\section{$N$-[3-Acetylamino-2-(3-cyclopropanecarbonyl-7-methoxy-naphthalen-1-yl)propyl]-}

cyclopropanoate ester (8). Recrystallized from acetonitrile as a white solid (15\% yield); Mp 108-110 ${ }^{\circ} \mathrm{C}$; MS (APCI, pos. $30 \mathrm{~V}$ ) $\mathrm{m} / z:[\mathrm{M}+\mathrm{H}]^{+}, 410.25 ;{ }^{1} \mathrm{H}$ NMR (DMSO- $d_{6}$ ): $\delta 0.72-0.78$ $(\mathrm{m}, 8 \mathrm{H}), 1.46-1.54(\mathrm{~m}, 2 \mathrm{H}), 1.78(\mathrm{~s}, 3 \mathrm{H}), 3.30(\mathrm{~m}, 1 \mathrm{H}), 3.50(\mathrm{~m}, 1 \mathrm{H}), 3.95(\mathrm{~s}, 3 \mathrm{H}), 3.99(\mathrm{~m}$, 1H), $4.35(\mathrm{~m}, 1 \mathrm{H}), 4.46(\mathrm{~m}, 1 \mathrm{H}), 7.16(\mathrm{dd}, 1 \mathrm{H}, J=9.0, J=2.0), 7.33(\mathrm{~m}, 1 \mathrm{H}), 7.44(\mathrm{~m}, 1 \mathrm{H})$, 
$7.68(\mathrm{~d}, 1 \mathrm{H}, J=2.0), 7.76(\mathrm{~m}, 1 \mathrm{H}), 7.86(\mathrm{~d}, 1 \mathrm{H}, J=9.0), 8.08(\mathrm{br} \mathrm{s}, 1 \mathrm{H}) ; \mathrm{IR}$ (neat, $\left.\mathrm{cm}^{-1}\right): 3341$

$(\mathrm{NH}), 1717(\mathrm{C}=\mathrm{O}), 1653(\mathrm{C}=\mathrm{O}), 1643(\mathrm{C}=\mathrm{O})$; Anal. $\left(\mathrm{C}_{24} \mathrm{H}_{27} \mathrm{NO}_{5}\right) \mathrm{C}, \mathrm{H}, \mathrm{N}$.

\section{$N$-[2-(3-Cyclopropanecarbonyl-7-methoxy-naphthalen-1-yl)-3-hydroxy-propyl]-}

acetamide (9). The amidoester $8(0.4 \mathrm{~g}, 1.0 \mathrm{mmol})$ was dissolved in methanol $(10 \mathrm{~mL})$ then 5 $\mathrm{mL}$ of an aqueous solution of $\mathrm{NaOH}(2 \mathrm{~N})$ was added. The mixture was stirred at room temperature for $48 \mathrm{~h}$, concentrated under reduced pressure, poured into water $(50 \mathrm{~mL})$ and extracted with ethyl acetate. The organic layer was washed with brine, dried over $\mathrm{MgSO}_{4}$ and evaporated under reduced pressure to give the desired product after recrystallisation from acetonitrile; White solid (61\% yield); Mp 158-160 ${ }^{\circ} \mathrm{C}$; MS (APCI, pos. $30 \mathrm{~V}$ ) $\mathrm{m} / z:[\mathrm{M}+\mathrm{H}]^{+}$, 342.18; ${ }^{1} \mathrm{H}$ NMR (DMSO-d $): \delta 1.02-1.07$ (m, 4H), 1.78 (s, 3H), $3.04(\mathrm{~m}, 1 \mathrm{H}), 3.38-3.44$ (m, 2H), 3.77-3.83 (m, 3H), $3.98(\mathrm{~s}, 3 \mathrm{H}), 4.75($ br s, $1 \mathrm{H}), 7.25(\mathrm{dd}, 1 \mathrm{H}, J=9.0, J=2.0), 7.68(\mathrm{~d}$, $1 \mathrm{H}, J=2.0), 7.91-7.95(\mathrm{~m}, 1 \mathrm{H}), 8.00($ br s, $1 \mathrm{H}), 8.08(\mathrm{~d}, 1 \mathrm{H}, J=9.0), 8.63-8.66(\mathrm{~m}, 1 \mathrm{H}) ;{ }^{13} \mathrm{C}$ NMR (DMSO- $\left.d_{6}\right): \delta 11.6(2 \mathrm{C}), 16.8,23.0,41.7,42.2,55.9,63.1,103.1,119.1,122.4,126.8$, $128.5,130.6,132.5,132.7,137.5,160.0,170.2,199.9 ;$ IR (neat, $\left.\mathrm{cm}^{-1}\right): 3341-3199(\mathrm{NH}, \mathrm{OH})$, $1728(\mathrm{C}=\mathrm{O}), 1643(\mathrm{C}=\mathrm{O})$; Anal. $\left(\mathrm{C}_{20} \mathrm{H}_{23} \mathrm{NO}_{4}\right) \mathrm{C}, \mathrm{H}, \mathrm{N}$.

Methyl 2-cyano-2-(3-cyclopropanecarbonyl-7-methoxy-naphthalen-1-yl)acetate (10a). Prepared from 1 as described for 8a; Recrystallized from ethanol as a yellow solid (86\% yield); Mp $144-146{ }^{\circ} \mathrm{C}$; MS (APCI, pos. $30 \mathrm{~V}$ ) $\mathrm{m} / z:[\mathrm{M}+\mathrm{H}]^{+}, 324.20 ;{ }^{1} \mathrm{H}$ NMR (DMSO$\left.d_{6}\right): \delta 1.08-1.15(\mathrm{~m}, 4 \mathrm{H}), 3.09(\mathrm{~m}, 1 \mathrm{H}), 3.75(\mathrm{~s}, 3 \mathrm{H}), 3.95(\mathrm{~s}, 3 \mathrm{H}), 6.48(\mathrm{~s}, 1 \mathrm{H}), 7.41-7.48$ $(\mathrm{m}, 2 \mathrm{H}), 8.12(\mathrm{~d}, 1 \mathrm{H}, J=2.4), 8.21(\mathrm{~d}, 1 \mathrm{H}, J=9.0), 8.92(\mathrm{~m}, 1 \mathrm{H}) ; \mathrm{IR}$ (neat, $\left.\mathrm{cm}^{-1}\right): 2242$ $(\mathrm{CN}), 1747(\mathrm{C}=\mathrm{O}), 1649(\mathrm{C}=\mathrm{O})$.

\section{Methyl 2-cyano-2-(3-cyclobutanecarbonyl-7-methoxy-naphthalen-1-yl)acetate (10b).}

Prepared from compound $\mathbf{1}$ according to procedure described for $\mathbf{8 a}$; Recrystallized from ethanol as a white solid (62\% yield); Mp 132-134 ${ }^{\circ} \mathrm{C}$; MS (APCI, pos. $\left.30 \mathrm{~V}\right) \mathrm{m} / \mathrm{z}:[\mathrm{M}+\mathrm{H}]^{+}$, 338.21; ${ }^{1} \mathrm{H}$ NMR (DMSO-d $): \delta 1.82(\mathrm{~m}, 1 \mathrm{H}), 2.08(\mathrm{~m}, 1 \mathrm{H}), 2.26-2.33(\mathrm{~m}, 4 \mathrm{H}), 3.74(\mathrm{~s}$, 
$3 \mathrm{H}), 3.92(\mathrm{~s}, 3 \mathrm{H}), 4.27(\mathrm{~m}, 1 \mathrm{H}), 6.48(\mathrm{~s}, 1 \mathrm{H}), 7.36(\mathrm{~d}, 1 \mathrm{H}, J=1.6), 7.40(\mathrm{dd}, 1 \mathrm{H}, J=9.0, J=$ 2.4), $8.09(\mathrm{~d}, 1 \mathrm{H}, J=2.4), 8.18(\mathrm{~d}, 1 \mathrm{H}, J=9.0), 8.59(\mathrm{~d}, 1 \mathrm{H}, J=1.6)$; IR (neat, $\left.\mathrm{cm}^{-1}\right): 2242$ $(\mathrm{CN}), 1748(\mathrm{C}=\mathrm{O}), 1662(\mathrm{C}=\mathrm{O})$.

3-Hydroxy-2-(3-cyclopropylmethyl-7-methoxy-naphthalen-1-yl)propylamine hydrochloride (11a). This compound was prepared from 10a according to the procedure described for 3 . Recrystallized from acetonitrile as a white solid (50\% yield); Mp 174-176 ${ }^{\circ} \mathrm{C}$; MS (APCI, pos. $30 \mathrm{~V}) \mathrm{m} / z:[\mathrm{M}+\mathrm{H}]^{+}, 322.12 ;{ }^{1} \mathrm{H}$ NMR (DMSO-d $): \delta 0.20-0.25(\mathrm{~m}, 2 \mathrm{H}), 0.46-0.50(\mathrm{~m}, 2 \mathrm{H}), 1.05$ (m, 1H), 2.60-2.63 (m, 2H), 3.18-3.21 (m, 2H), 3.70-.74 (m, 2H), $3.93(\mathrm{~m}, 1 \mathrm{H}), 3.90(\mathrm{~s}, 3 \mathrm{H})$, 5.31 (br s, 1H), $7.17(\mathrm{dd}, 1 \mathrm{H}, J=9.0, J=2.4), 7.35(\mathrm{~d}, 1 \mathrm{H}, J=2.0), 7.47(\mathrm{~d}, 1 \mathrm{H}, J=2.4), 7.62$ $(\mathrm{d}, 1 \mathrm{H}, J=2.0), 7.80(\mathrm{~d}, 1 \mathrm{H}, J=9.0), 8.05(\mathrm{br} \mathrm{s}, 3 \mathrm{H})$; IR (neat, $\left.\mathrm{cm}^{-1}\right): 3314-2827\left(\mathrm{NH}_{2}, \mathrm{OH}\right)$.

\section{3-Hydroxy-2-(3-cyclobutylmethyl-7-methoxy-naphthalen-1-yl)propylamine hydrochloride}

(11b). Prepared from 10b according to the procedure described for compound $\mathbf{3}$; Recrystallized from acetonitrile as a white solid (52\% yield); $\mathrm{Mp} 144-146{ }^{\circ} \mathrm{C}$; MS (APCI, pos. $\left.30 \mathrm{~V}\right) \mathrm{m} / \mathrm{z}$ : $[\mathrm{M}+\mathrm{H}]^{+}, 336.15 ;{ }^{1} \mathrm{H}$ NMR (DMSO-d $): \delta 1.74-1.82(\mathrm{~m}, 4 \mathrm{H}), 1.97-1.99(\mathrm{~m}, 2 \mathrm{H}), 2.61(\mathrm{~m}, 1 \mathrm{H})$, $2.77(\mathrm{~d}, 2 \mathrm{H}, J=7.8), 3.15(\mathrm{~m}, 1 \mathrm{H}), 3.39(\mathrm{~m}, 1 \mathrm{H}), 3.70-3.74(\mathrm{~m}, 2 \mathrm{H}), 3.92(\mathrm{~s}, 3 \mathrm{H}), 3.94(\mathrm{~m}$, 1H), $5.21($ br s, $1 \mathrm{H}), 7.16(\mathrm{dd}, 1 \mathrm{H}, J=9.0, J=2.4), 7.27(\mathrm{~d}, 1 \mathrm{H}, J=1.6), 7.47(\mathrm{~d}, 1 \mathrm{H}, J=2.4)$, 7.49 (d, $1 \mathrm{H}, J=1.6), 7.77(\mathrm{~d}, 1 \mathrm{H}, J=9.0), 8.11$ (br s, $2 \mathrm{H})$; IR (neat, $\left.\mathrm{cm}^{-1}\right): 3395-2827\left(\mathrm{NH}_{2}\right.$, $\mathrm{OH})$.

Synthesis of ureas and thioureas 12a-d. These compounds were prepared from compound 11a according to the procedure described for 4 (route 2).

$N$-[2-[3-(Cyclopropylmethyl)-7-methoxy-1-naphthyl]-3-hydroxy-propyl]acetamide (12a). Recrystallized from acetonitrile as a white solid (83\% yield); Mp 154-156 ${ }^{\circ} \mathrm{C}$; MS (APCI, pos. $30 \mathrm{~V}) \mathrm{m} / z:[\mathrm{M}+\mathrm{H}]^{+}, 328.18 ;{ }^{1} \mathrm{H}$ NMR (DMSO- $\left.d_{6}\right): \delta 0.18-0.22(\mathrm{~m}, 2 \mathrm{H}), 0.45-0.49(\mathrm{~m}$, 2H), $1.03(\mathrm{~m}, 1 \mathrm{H}), 1.78(\mathrm{~s}, 3 \mathrm{H}), 2.60(\mathrm{~d}, 2 \mathrm{H}, J=6.7), 3.39(\mathrm{~m}, 1 \mathrm{H}), 3.46(\mathrm{~m}, 1 \mathrm{H}), 3.66-3.84$ (m, 3H), $3.91(\mathrm{~s}, 3 \mathrm{H}), 4.72($ br s, $1 \mathrm{H}), 7.12(\mathrm{dd}, 1 \mathrm{H}, J=9.0, J=2.4), 7.33(\mathrm{~d}, 1 \mathrm{H}, J=2.0)$, 
7.50-7.55 (m, 2H), $7.75(\mathrm{~d}, 1 \mathrm{H}, J=9.0), 7.91(\mathrm{br} \mathrm{s}, 1 \mathrm{H}) ;{ }^{13} \mathrm{C}$ NMR (DMSO- $\left.d_{6}\right): \delta 5.0(2 \mathrm{C})$, $12.3,23.1,41.6,42.3,55.6(2 \mathrm{C}), 63.3,102.8,118.0,125.1,126.4,129.6,130.2,132.3$, 136.5, 136.7, 157.3, 170.1; IR (neat, $\mathrm{cm}^{-1}$ ): $3260(\mathrm{NH}), 2993-2845(\mathrm{OH}), 1634(\mathrm{C}=\mathrm{O})$; Anal. $\left(\mathrm{C}_{20} \mathrm{H}_{25} \mathrm{NO}_{3}\right) \mathrm{C}, \mathrm{H}, \mathrm{N}$.

\section{$N$-[2-[3-(Cyclopropylmethyl)-7-methoxy-1-naphthyl]-3-hydroxy-propyl]propylamide}

(12b). Recrystallized from toluene as a white solid (64\% yield); Mp 104-106 ${ }^{\circ} \mathrm{C}$; MS (APCI, pos. $30 \mathrm{~V}$ ) $\mathrm{m} / z:[\mathrm{M}+\mathrm{H}]^{+}, 342.20 ;{ }^{1} \mathrm{H}$ NMR (DMSO- $\left.d_{6}\right): \delta 0.20-0.24(\mathrm{~m}, 2 \mathrm{H}), 0.44-0.48(\mathrm{~m}$, 2H), 0.89-0.95 (m, 3H), $1.03(\mathrm{~m}, 1 \mathrm{H}), 2.00-2.05(\mathrm{~m}, 2 \mathrm{H}), 2.60(\mathrm{~d}, 2 \mathrm{H}, J=6.4), 3.40-3.47(\mathrm{~m}$, 2H), 3.70-3.78 (m, 3H), $3.91(\mathrm{~s}, 3 \mathrm{H}), 4.73$ (br s, 1H), $7.12(\mathrm{dd}, 1 \mathrm{H}, J=9.0, J=2.4), 7.33$ (d, $1 \mathrm{H}, J=1.6), 7.50-7.54(\mathrm{~m}, 2 \mathrm{H}), 7.77(\mathrm{~d}, 1 \mathrm{H}, J=9.0), 7.81(\mathrm{br} \mathrm{s}, 1 \mathrm{H}) ;{ }^{13} \mathrm{C}$ NMR (DMSO- $\left.d_{6}\right)$ : $\delta 5.1(2 \mathrm{C}), 10.5,12.4,29.1,41.6(2 \mathrm{C}), 42.3,55.7,63.4,102.9,118.1,125.2,126.5,129.6$, 130.2, 132.3, 136.5, 136.7, 157.3, 173.8; IR (neat, $\left.\mathrm{cm}^{-1}\right): 3238(\mathrm{NH}), 3077-2881(\mathrm{OH}), 1639$ $(\mathrm{C}=\mathrm{O})$; Anal. $\left(\mathrm{C}_{21} \mathrm{H}_{27} \mathrm{NO}_{3}\right) \mathrm{C}, \mathrm{H}, \mathrm{N}$.

\section{$N$-[2-[3-(Cyclopropylmethyl)-7-methoxy-1-naphthyl]-3-hydroxy-propyl]cyclopropylamide}

(12c). Recrystallized from toluene as a white solid (62\% yield); Mp 142-144 ${ }^{\circ} \mathrm{C}$; MS (APCI, pos. $30 \mathrm{~V}) m / z:[\mathrm{M}+\mathrm{H}]^{+}, 354.21 ;{ }^{1} \mathrm{H}$ NMR (DMSO- $\left.d_{6}\right): \delta 0.20-0.24(\mathrm{~m}, 2 \mathrm{H}), 0.45-0.48(\mathrm{~m}$, 2H), 0.54-0.59 (m, 2H), 0.61-0.65 (m, 2H), $1.03(\mathrm{~m}, 1 \mathrm{H}), 1.48(\mathrm{~m}, 1 \mathrm{H}), 2.60(\mathrm{~d}, 2 \mathrm{H}, J=7.0)$, 3.45-3.50 (m, 2H), 3.68-3.78 (m, 3H), $3.89(\mathrm{~s}, 3 \mathrm{H}), 4.75(\mathrm{br} \mathrm{s}, 1 \mathrm{H}), 7.13(\mathrm{dd}, 1 \mathrm{H}, J=9.0, J=$ 2.4), $7.32(\mathrm{~d}, 1 \mathrm{H}, J=2.0), 7.51(\mathrm{~d}, 1 \mathrm{H}, J=2.4), 7.55(\mathrm{~d}, 1 \mathrm{H}, J=2.0), 7.76(\mathrm{~d}, 1 \mathrm{H}, J=9.0)$, 8.10 (br s, $1 \mathrm{H}) ;{ }^{13} \mathrm{C}$ NMR (DMSO- $\left.d_{6}\right): \delta 5.1$ (2C), $6.6(2 \mathrm{C}), 12.4,14.2,41.6(2 \mathrm{C}), 42.6,55.6$, $63.5,103.0,118.2,125.1,126.5,129.7,130.2,132.3,136.5,136.8,157.5,173.4$; IR (neat, $\mathrm{cm}^{-}$ $\left.{ }^{1}\right): 3396(\mathrm{NH}), 3073-2914(\mathrm{OH}), 1647(\mathrm{C}=\mathrm{O})$; Anal. $\left(\mathrm{C}_{22} \mathrm{H}_{27} \mathrm{NO}_{3}\right) \mathrm{C}, \mathrm{H}, \mathrm{N}$.

\section{$N$-Cyclobutylcarbonyl-[2-(3-cyclopropylmethyl-7-methoxy-naphthalen-1-yl)-3-hydroxy-}

propyl]amide (12d). Recrystallized from acetonitrile as a white solid (42\% yield); Mp 94-96 ${ }^{\circ} \mathrm{C}$; MS (APCI, pos. $\left.30 \mathrm{~V}\right) \mathrm{m} / z:[\mathrm{M}+\mathrm{H}]^{+}, 368.22 ;{ }^{1} \mathrm{H}$ NMR (DMSO- $\left.d_{6}\right): \delta 0.20-0.25(\mathrm{~m}, 2 \mathrm{H})$, 
0.45-0.48 (m, 2H), $1.03(\mathrm{~m}, 1 \mathrm{H}), 1.64-2.10(\mathrm{~m}, 6 \mathrm{H}), 2.60(\mathrm{~d}, 2 \mathrm{H}, J=6.6), 2.90(\mathrm{~m}, 1 \mathrm{H}), 3.42-$ $3.45(\mathrm{~m}, 2 \mathrm{H}), 3.68-3.72(\mathrm{~m}, 3 \mathrm{H}), 3.91(\mathrm{~s}, 3 \mathrm{H}), 4.72(\mathrm{br} \mathrm{s}, 1 \mathrm{H}), 7.13(\mathrm{dd}, 1 \mathrm{H}, J=9.0, J=2.4)$, $7.32(\mathrm{~d}, 1 \mathrm{H}, J=2.0), 7.52-7.55(\mathrm{~m}, 2 \mathrm{H}), 7.66(\mathrm{br} s, 1 \mathrm{H}), 7.75(\mathrm{~d}, 1 \mathrm{H}, J=9.0) ;{ }^{13} \mathrm{C}$ NMR (DMSO-d $): \delta 5.1(2 \mathrm{C}), 12.3,18.3,25.1$ (2C), 39.2, 41.5 (2C), 42.4, 55.6, 63.4, 102.9, 118.0, 125.1, 126.5, 129.6, 130.2, 132.3, 136.5, 136.7, 157.3, 174.7; IR (neat, $\left.\mathrm{cm}^{-1}\right): 3304(\mathrm{NH}), 3074-$ $2821(\mathrm{OH}), 1636(\mathrm{C}=\mathrm{O})$; Anal. $\left(\mathrm{C}_{23} \mathrm{H}_{29} \mathrm{NO}_{3}\right) \mathrm{C}, \mathrm{H}, \mathrm{N}$.

\section{$N$-[2-[3-(Cyclopropylmethyl)-7-methoxy-1-naphthyl]-3-hydroxy-propyl]fluoro-}

acetamide (12e). To a solution of $11 \mathrm{a}(2.0 \mathrm{~g}, 6.2 \mathrm{mmol})$ in a mixture of $\mathrm{H}_{2} \mathrm{O}-\mathrm{EtOAc}(40: 60$ $\mathrm{mL})$ was added $\mathrm{K}_{2} \mathrm{CO}_{3}(2.6 \mathrm{~g}, 18.8 \mathrm{mmol})$. The mixture was stirred at room temperature for 2 $\mathrm{h}$ and the two phases were separated. The organic phase was washed with water, dried over $\mathrm{MgSO}_{4}$ and evaporated under reduced pressure. The obtained oil was then dissolved in $25 \mathrm{~mL}$ of 2,2,2-trifluoroethanol and ethyl fluoroacetate $(2.4 \mathrm{~mL}, 24.8 \mathrm{mmol})$ was added dropwise cautiously. The reaction mixture was stirred and refluxed for $12 \mathrm{~h}$. After cooling, the mixture was poured into water $(40 \mathrm{~mL})$, extracted twice with ethyl ether $(25 \mathrm{~mL})$ and the organic layers were dried over $\mathrm{MgSO}_{4}$ and evaporated under reduced pressure. The obtained residue was then solubilized in $20 \mathrm{~mL}$ of methanol and $10 \mathrm{~mL}$ of a solution of $\mathrm{NaOH}(2 \mathrm{~N})$ was added. The mixture was heated at $40{ }^{\circ} \mathrm{C}$ for $30 \mathrm{~min}$, poured into water and acidified with an aqueous solution of $\mathrm{HCl}(1 \mathrm{M})$. The mixture was then extracted with diethyl ether and the organic phase was washed, dried over $\mathrm{MgSO}_{4}$ and evaporated under reduced pressure to give the desired product after recrystallisation from isopropyl ether. White solid (33\% yield); Mp 88-90 ${ }^{\circ} \mathrm{C}$; MS (APCI, pos. $\left.30 \mathrm{~V}\right) \mathrm{m} / z:[\mathrm{M}+\mathrm{H}]^{+}, 346.18 ;{ }^{1} \mathrm{H}$ NMR (DMSO- $\left.d_{6}\right): \delta 0.20-0.24(\mathrm{~m}$, $2 \mathrm{H}), 0.45-0.48(\mathrm{~m}, 2 \mathrm{H}), 1.00-1.03(\mathrm{~m}, 1 \mathrm{H}), 2.61(\mathrm{~d}, 2 \mathrm{H}, J=6.8), 3.47-3.50(\mathrm{~m}, 1 \mathrm{H}), 3.55-3.57$ (m, 1H), 3.75-3.83 (m, 3H), $3.91(\mathrm{~s}, 3 \mathrm{H}), 4.76(\mathrm{~d}, 2 \mathrm{H}, J=47.1), 4.79($ br s, $1 \mathrm{H}), 7.13(\mathrm{dd}, 1 \mathrm{H}$, $J=9.0, J=2.4), 7.37(\mathrm{~d}, 1 \mathrm{H}, J=1.6), 7.55(\mathrm{~d}, 1 \mathrm{H}, J=1.6), 7.57(\mathrm{~d}, 1 \mathrm{H}, J=2.4), 7.76(\mathrm{~d}, 1 \mathrm{H}$, 
$J=9.0$ ), 8.25 (br s, 1H); IR (neat, $\left.\mathrm{cm}^{-1}\right): 3248,3077-2832,1647$; Anal. $\left(\mathrm{C}_{20} \mathrm{H}_{24} \mathrm{FNO}_{3}\right) \mathrm{C}, \mathrm{H}$, N.

Synthesis of ureas and thioureas 12f-j. To a suspension of compound 11a $(6.2 \mathrm{mmol})$ in dichloromethane $(60 \mathrm{~mL})$ at $0{ }^{\circ} \mathrm{C}$, were added respectively triethylamine $(12.4 \mathrm{mmol})$ and the corresponding isocyanate or isothiocyanate $(6.3 \mathrm{mmol})$. The mixture was left to stir for 2 $\mathrm{h}$ and the solid formed was filtered, washed with diethyl ether and recrystallized to lead to the desired product.

\section{1-[2-(3-Cyclopropylmethyl-7-methoxy-naphthalen-1-yl)-3-hydroxy-propyl]-3-ethyl-}

urea (12f). Recrystallized from toluene as a white solid (72\% yield); Mp 116-118 ${ }^{\circ} \mathrm{C}$; MS (APCI, pos. $30 \mathrm{~V}) \mathrm{m} / z:[\mathrm{M}+\mathrm{H}]^{+}, 357.19 ;{ }^{1} \mathrm{H}$ NMR (DMSO-d 6$): \delta 0.20-0.25(\mathrm{~m}, 2 \mathrm{H}), 0.45-$ $0.49(\mathrm{~m}, 2 \mathrm{H}), 0.91-0.96(\mathrm{~m}, 3 \mathrm{H}), 1.05(\mathrm{~m}, 1 \mathrm{H}), 2.61(\mathrm{~d}, 2 \mathrm{H}, J=6.6), 2.97-3.00(\mathrm{~m}, 2 \mathrm{H})$, 3.38-3.42 (m, 2H), 3.66-3.72 (m, 3H), 3.91 (s, 3H), 4.82 (br s, 1H), 5.85 (br s, 2H), 7.13 (dd, $1 \mathrm{H}, J=9.0, J=2.4), 7.33(\mathrm{~m}, 1 \mathrm{H}), 7.53(\mathrm{~d}, 1 \mathrm{H}, J=2.4), 7.56(\mathrm{~m}, 1 \mathrm{H}), 7.75(\mathrm{~d}, 1 \mathrm{H}, J=9.0)$; ${ }^{13} \mathrm{C}$ NMR (DMSO- $\left.d_{6}\right): \delta 5.1(2 \mathrm{C}), 12.4,16.2,34.6,42.2(2 \mathrm{C}), 43.2,55.6,63.6,102.8,118.1$, 125.0, 126.4, 129.6, 130.1, 132.2, 136.7, 136.8, 157.3, 158.7; IR (neat, $\mathrm{cm}^{-1}$ ): 3368-3291 (NH), 3074-2821(OH), $1653(\mathrm{C}=\mathrm{O})$; Anal. $\left(\mathrm{C}_{21} \mathrm{H}_{28} \mathrm{~N}_{2} \mathrm{O}_{3}\right) \mathrm{C}, \mathrm{H}, \mathrm{N}$.

\section{1-[2-(3-Cyclopropylmethyl-7-methoxy-naphthalen-1-yl)-3-hydroxy-propyl]-3-propyl-}

urea (12g). Recrystallized from toluene-cyclohexane (1:1) as a white solid (30\% yield); Mp 92-94 ${ }^{\circ} \mathrm{C}$; MS (APCI, pos. $\left.30 \mathrm{~V}\right) \mathrm{m} / z:[\mathrm{M}+\mathrm{H}]^{+}, 371.22 ;{ }^{1} \mathrm{H}$ NMR (DMSO- $\left.d_{6}\right): \delta 0.22-0.25(\mathrm{~m}$, $2 \mathrm{H}), 0.45-0.50(\mathrm{~m}, 2 \mathrm{H}), 0.78-0.83(\mathrm{~m}, 3 \mathrm{H}), 1.05(\mathrm{~m}, 1 \mathrm{H}), 1.31-1.34(\mathrm{~m}, 2 \mathrm{H}), 2.62(\mathrm{~d}, 2 \mathrm{H}, J=$ 6.6), 2.91-2.95 (m, 2H), 3.42-3.45 (m, 2H), 3.66-3.69 (m, 3H), $3.91(\mathrm{~s}, 3 \mathrm{H}), 4.82$ (br s, $1 \mathrm{H})$, 5.80 (br s, $1 \mathrm{H}), 5.90$ (br s, $1 \mathrm{H}), 7.13(\mathrm{dd}, 1 \mathrm{H}, J=9.0, J=2.4), 7.34(\mathrm{~d}, 1 \mathrm{H}, J=1.6), 7.52(\mathrm{~d}$, $1 \mathrm{H}, J=2.4), 7.56(\mathrm{~d}, 1 \mathrm{H}, J=1.6), 7.76(\mathrm{~d}, 1 \mathrm{H}, J=9.0) ;{ }^{13} \mathrm{C}$ NMR (DMSO- $\left.d_{6}\right): \delta 5.0(2 \mathrm{C})$ $11.8,12.4,23.7,41.6(2 \mathrm{C}), 42.1,43.1,55.5,63.6,102.8,118.0,125.0,126.3,129.5,130.1$, 
132.3, 136.7, 136.8, 157.3, 158.9; IR (neat, $\left.\mathrm{cm}^{-1}\right)$ : 3362-3290 (NH), 3011-2877(OH), 1654 $(\mathrm{C}=\mathrm{O})$; Anal. $\left(\mathrm{C}_{22} \mathrm{H}_{30} \mathrm{~N}_{2} \mathrm{O}_{3}\right) \mathrm{C}, \mathrm{H}, \mathrm{N}$.

\section{1-[2-(3-Cyclopropylmethyl-7-methoxy-naphthalen-1-yl)-3-hydroxypropyl]-3-methyl-}

thiourea (12h). Recrystallized from toluene as a white solid (42\% yield); Mp 96-98 ${ }^{\circ} \mathrm{C}$; MS (APCI, pos. $30 \mathrm{~V}$ ) $\mathrm{m} / z:[\mathrm{M}+\mathrm{H}]^{+}, 359.18 ;{ }^{1} \mathrm{H}$ NMR (DMSO-d $): \delta 0.20-024(\mathrm{~m}, 2 \mathrm{H}), 0.45-0.48$ $(\mathrm{m}, 2 \mathrm{H}), 1.05(\mathrm{~m}, 1 \mathrm{H}), 2.61(\mathrm{~d}, 2 \mathrm{H}, J=6.6), 2.73-2.77(\mathrm{~m}, 2 \mathrm{H}), 3.72-3.80(\mathrm{~m}, 5 \mathrm{H}), 3.85-3.94$ (m, 4H), $4.78($ br s, $1 \mathrm{H}), 7.12(\mathrm{dd}, 1 \mathrm{H}, J=9.0, J=2.4), 7.32-7.38(\mathrm{~m}, 3 \mathrm{H}), 7.54-7.57(\mathrm{~m}, 2 \mathrm{H})$, $7.76(\mathrm{~d}, 1 \mathrm{H}, J=9.0) ;{ }^{13} \mathrm{C}$ NMR (DMSO- $\left.d_{6}\right): \delta 5.1(2 \mathrm{C}), 12.4(2 \mathrm{C}), 41.6(2 \mathrm{C}), 41.8,55.8,63.9$, 103.0, 118.2, 125.2, 126.6 (2C), 129.6 (2C), 130.2, 132.3, 136.8, 157.3; IR (neat, $\mathrm{cm}^{-1}$ ): 3264 (NH), 3060-2831 (OH); Anal. $\left(\mathrm{C}_{20} \mathrm{H}_{26} \mathrm{~N}_{2} \mathrm{O}_{2} \mathrm{~S}\right) \mathrm{C}, \mathrm{H}, \mathrm{N}$.

\section{1-[2-(3-Cyclopropylmethyl-7-methoxy-naphthalen-1-yl)-3-hydroxypropyl]-3-ethyl-}

thiourea (12i). Recrystallized from toluene as a white solid (51\% yield); $\mathrm{Mp} 130-132{ }^{\circ} \mathrm{C}$; MS (APCI, pos. $30 \mathrm{~V}) \mathrm{m} / z:[\mathrm{M}+\mathrm{H}]^{+}, 373.20 ;{ }^{1} \mathrm{H}$ NMR (DMSO- $\left.d_{6}\right): \delta 0.20-0.23(\mathrm{~m}, 2 \mathrm{H})$, 0.46-0.49 (m, 2H), 0.98-1.02 (m, 3H), $1.04(\mathrm{~m}, 1 \mathrm{H}), 2.61(\mathrm{~d}, 2 \mathrm{H}, J=6.6), 3.27-3.31(\mathrm{~m}$, 2H), 3.72-3.80 (m, 4H), 3.86-3.92 (m, 4H), 4.81 (br s, 1H), $7.12(\mathrm{dd}, 1 \mathrm{H}, J=9.0, J=2.4)$, 7.26 (br s, 1H), $7.36(\mathrm{~m}, 1 \mathrm{H}), 7.41($ br s, $1 \mathrm{H}), 7.54-7.57(\mathrm{~m}, 2 \mathrm{H}), 7.75(\mathrm{~d}, 1 \mathrm{H}, J=9.0) ;{ }^{13} \mathrm{C}$ NMR (DMSO- $\left.d_{6}\right): \delta 5.1$ (2C), 12.4, 14.9, 41.8 (2C), 42.3 (2C), 55.7, 63.9, 102.9, 118.2, 125.2, 126.5, 129.6, 130.2, 132.4, 136.6, 136.8, 157.3, 170.1; IR (neat, $\mathrm{cm}^{-1}$ ): 3347-2994 (NH), 3060-2831 (OH); Anal. $\left(\mathrm{C}_{21} \mathrm{H}_{28} \mathrm{~N}_{2} \mathrm{O}_{2} \mathrm{~S}\right) \mathrm{C}, \mathrm{H}, \mathrm{N}$.

\section{1-[2-(3-Cyclopropylmethyl-7-methoxy-naphthalen-1-yl)-3-hydroxypropyl]-3-propyl-}

thiourea (12j). Recrystallized from cyclohexane-toluene (1:1) as a white solid (50\% yield); Mp 122-124 ${ }^{\circ} \mathrm{C}$; MS (APCI, pos. $\left.30 \mathrm{~V}\right) \mathrm{m} / z:[\mathrm{M}+\mathrm{H}]^{+}, 387.21 ;{ }^{1} \mathrm{H}$ NMR (DMSO-d $): \delta 0.20-$ $0.23(\mathrm{~m}, 2 \mathrm{H}), 0.47-0.50(\mathrm{~m}, 2 \mathrm{H}), 0.78-0.81(\mathrm{~m}, 3 \mathrm{H}), 1.03(\mathrm{~m}, 1 \mathrm{H}), 1.39-1.41(\mathrm{~m}, 2 \mathrm{H}), 2.62(\mathrm{~d}$, $2 \mathrm{H}, J=6.6), 3.25-3.30(\mathrm{~m}, 2 \mathrm{H}), 3.72-3.79(\mathrm{~m}, 4 \mathrm{H}), 3.87-3.93(\mathrm{~m}, 4 \mathrm{H}), 4.80(\mathrm{br} \mathrm{s}, 1 \mathrm{H}), 7.12$ $(\mathrm{dd}, 1 \mathrm{H}, J=9.0, J=2.4), 7.25(\mathrm{br} \mathrm{s}, 1 \mathrm{H}), 7.36(\mathrm{~d}, 1 \mathrm{H}, J=1.6), 7.42($ br s, $1 \mathrm{H}), 7.55-7.57(\mathrm{~m}$, 
2H), $7.76(\mathrm{~d}, 1 \mathrm{H}, J=9.0) ;{ }^{13} \mathrm{C}$ NMR (DMSO- $\left.d_{6}\right): \delta 5.0(2 \mathrm{C}), 11.8(2 \mathrm{C}), 12.4(2 \mathrm{C}), 22.4,41.8$

(2C), 55.7, 63.9, 102.9, 118.1, 125.2, 126.5, 129.6, 130.1, 132.4, 136.6, 136.8, 157.3, 170.7;

IR (neat, $\mathrm{cm}^{-1}$ ): 3360-3088 (NH), 2994-2831 (OH); Anal. $\left(\mathrm{C}_{22} \mathrm{H}_{30} \mathrm{~N}_{2} \mathrm{O}_{2} \mathrm{~S}\right) \mathrm{C}, \mathrm{H}, \mathrm{N}$.

General procedure for the synthesis of compounds 13a-13b. These two compounds were prepared from $\mathbf{1 1 b}$ according to procedure described for $\mathbf{4}$.

\section{$N$-[3-Hydroxy-2-(3-cyclobutylmethyl-7-methoxy-naphthalen-1-yl)propyl]acetamide}

(13a). Recrystallized from acetonitrile as a white solid (86\% yield); Mp 140-142 ${ }^{\circ} \mathrm{C}$; MS (APCI, pos. $30 \mathrm{~V}) \mathrm{m} / z:[\mathrm{M}+\mathrm{H}]^{+}, 342.21 ;{ }^{1} \mathrm{H}$ NMR (DMSO-d $): \delta 1.72-1.82(\mathrm{~m}, 7 \mathrm{H}), 1.96-$ $1.99(\mathrm{~m}, 2 \mathrm{H}), 2.60(\mathrm{~m}, 1 \mathrm{H}), 2.76(\mathrm{~d}, 2 \mathrm{H}, J=7.7), 3.36(\mathrm{~m}, 1 \mathrm{H}), 3.45(\mathrm{~m}, 1 \mathrm{H}), 3.68-3.74$ (m, 3H), $3.91(\mathrm{~s}, 3 \mathrm{H}), 4.72($ br s, $1 \mathrm{H}), 7.12(\mathrm{dd}, 1 \mathrm{H}, J=9.0, J=2.4), 7.25(\mathrm{~d}, 1 \mathrm{H}, J=1.6)$, $7.43(\mathrm{~d}, 1 \mathrm{H}, J=1.6), 7.54(\mathrm{~d}, 1 \mathrm{H}, J=2.4), 7.73(\mathrm{~d}, 1 \mathrm{H}, J=9.0), 7.91(\mathrm{br} \mathrm{s}, 1 \mathrm{H}) ;{ }^{13} \mathrm{C} \mathrm{NMR}$ (DMSO-d $): \delta 18.4,23.0,28.1$ (2C), 37.1, 41.5, 42.2, 42.8, 55.8, 63.3, 102.7, 118.0, 125.2, $126.4,129.6,130.2,132.2,135.7,136.5,157.4,170.0$; IR (neat, $\mathrm{cm}^{-1}$ ): $3267(\mathrm{NH}), 3090-$ $2856(\mathrm{OH}), 1634(\mathrm{C}=\mathrm{O})$; Anal. $\left(\mathrm{C}_{21} \mathrm{H}_{27} \mathrm{NO}_{3}\right) \mathrm{C}, \mathrm{H}, \mathrm{N}$.

$N$-[3-Hydroxy-2-(3-cyclobutylmethyl-7-methoxy-naphthalen-1-yl)propyl]propylamide (13b). Recrystallized from acetonitrile as a white solid (50\% yield); Mp 88-90 ${ }^{\circ} \mathrm{C}$; MS (APCI, pos. $30 \mathrm{~V}) \mathrm{m} / z:[\mathrm{M}+\mathrm{H}]^{+}, 356.22 ;{ }^{1} \mathrm{H}$ NMR (DMSO- $\left.d_{6}\right): \delta 0.90-0.94(\mathrm{~m}, 3 \mathrm{H}), 1.72-$ $1.80(\mathrm{~m}, 4 \mathrm{H}), 1.92-2.04(\mathrm{~m}, 4 \mathrm{H}), 2.59(\mathrm{~m}, 1 \mathrm{H}), 2.75(\mathrm{~d}, 2 \mathrm{H}, J=7.7), 3.36(\mathrm{~m}, 1 \mathrm{H}), 3.47(\mathrm{~m}$, 1H), 3.68-3.76 (m, 3H), 3.90 (s, 3H), $4.72($ br s, $1 \mathrm{H}), 7.11(\mathrm{dd}, 1 \mathrm{H}, J=9.0, J=2.4), 7.23$ (d, $1 \mathrm{H}, J=1.6), 7.42(\mathrm{~d}, 1 \mathrm{H}, J=1.6), 7.52(\mathrm{~d}, 1 \mathrm{H}, J=2.4), 7.73(\mathrm{~d}, 1 \mathrm{H}, J=9.0), 7.80$ (br s, 1H); ${ }^{13} \mathrm{C}$ NMR (DMSO- $\left.d_{6}\right): \delta 10.4,18.4,23.2,28.1$ (2C), 37.1, 41.5, 42.2, 42.8, 55.7, 63.2, 102.7, 118.1, 125.3, 126.4, 129.5, 130.2, 132.1, 135.7, 136.5, 157.3, 170.0; IR (neat, $\mathrm{cm}^{-1}$ ): $3304(\mathrm{NH}), 2966-2845(\mathrm{OH}), 1637(\mathrm{C}=\mathrm{O})$; Anal. $\left(\mathrm{C}_{22} \mathrm{H}_{29} \mathrm{NO}_{3}\right) \mathrm{C}, \mathrm{H}, \mathrm{N}$.

$N$-[3-Hydroxy-2-(3-cyclopropylmethyl-7-methoxy-naphthalen-1-yl)propyl]fluoroacetamide (13c). Prepared from 11b following procedure described for 12e; Recrystallized 
from isopropyl ether as a white solid (34\% yield); Mp 90-92 ${ }^{\circ} \mathrm{C}$; MS (APCI, pos. $\left.30 \mathrm{~V}\right) \mathrm{m} / \mathrm{z}$ : $[\mathrm{M}+\mathrm{H}]^{+}, 360.19 ;{ }^{1} \mathrm{H}$ NMR (DMSO- $\left.d_{6}\right): \delta 1.73-1.81(\mathrm{~m}, 4 \mathrm{H}), 1.98-2.00(\mathrm{~m}, 2 \mathrm{H}), 2.60(\mathrm{~m}, 1 \mathrm{H})$, $2.76(\mathrm{~d}, 2 \mathrm{H}, J=7.7), 3.46(\mathrm{~m}, 1 \mathrm{H}), 3.55(\mathrm{~m}, 1 \mathrm{H}), 3.71-3.80(\mathrm{~m}, 3 \mathrm{H}), 3.90(\mathrm{~s}, 3 \mathrm{H}), 4.79(\mathrm{~d}$, $2 \mathrm{H}, J=46.9), 4.89$ (br s, $1 \mathrm{H}), 7.12(\mathrm{dd}, 1 \mathrm{H}, J=9.0, J=2.4), 7.28(\mathrm{~d}, 1 \mathrm{H}, J=1.6), 7.44(\mathrm{~d}$, $1 \mathrm{H}, J=1.6), 7.56(\mathrm{~d}, 1 \mathrm{H}, J=2.4), 7.74(\mathrm{~d}, 1 \mathrm{H}, J=9.0), 8.24(\mathrm{br} \mathrm{s}, 1 \mathrm{H})$; IR (neat, $\left.\mathrm{cm}^{-1}\right): 3249$ (NH), 3077-2832 (OH), $1647(\mathrm{C}=\mathrm{O})$; Anal. $\left(\mathrm{C}_{21} \mathrm{H}_{26} \mathrm{FNO}_{3}\right) \mathrm{C}, \mathrm{H}, \mathrm{N}$.

\section{Preparation of compounds 14a-b.}

Methyl $N$-[3-acetylamino-2-(3-acetyl-7-methoxy-naphthalen-1-yl)]propionate (14a). To a solution of $2 \mathbf{a}(3.0 \mathrm{~g}, 10.0 \mathrm{mmol})$ in dry dichloromethane $(50 \mathrm{~mL})$ at $0{ }^{\circ} \mathrm{C}$ was added, portionwise cautiously, aluminum chloride $(10.0 \mathrm{~g}, 75.0 \mathrm{mmol})$ and the mixture was stirred for $5 \mathrm{~min}$. Acetyle chloride $(0.8 \mathrm{~mL}, 11.0 \mathrm{mmol})$ was then added dropwise. The mixture was allowed to stir at room temperature for $1 \mathrm{~h}$, poured into water $(100 \mathrm{~mL})$ and the organic phase was washed with water, dried over $\mathrm{MgSO}_{4}$ and evaporated under reduced pressure. The white solid formed was recrystallized from acetonitrile (83\% yield); Mp 160$162{ }^{\circ} \mathrm{C}$; MS (APCI, pos. $\left.30 \mathrm{~V}\right) \mathrm{m} / z:[\mathrm{M}+\mathrm{H}]^{+}, 344.20 ;{ }^{1} \mathrm{H}$ NMR (DMSO- $\left.d_{6}\right): \delta 1.77(\mathrm{~s}, 3 \mathrm{H})$, $2.64(\mathrm{~s}, 3 \mathrm{H}), 3.48-3.52(\mathrm{~m}, 2 \mathrm{H}), 3.67(\mathrm{~s}, 3 \mathrm{H}), 4.00(\mathrm{~s}, 3 \mathrm{H}), 4.70(\mathrm{~m}, 1 \mathrm{H}), 7.31(\mathrm{dd}, 1 \mathrm{H}, J=$ 9.0, $J=2.4), 7.76(\mathrm{~d}, 1 \mathrm{H}, J=1.8), 7.82(\mathrm{~d}, 1 \mathrm{H}, J=2.4), 8.08(\mathrm{~d}, 1 \mathrm{H}, J=9.0), 8.30$ (br s, 1H), $8.58(\mathrm{~d}, 1 \mathrm{H}, J=1.8)$; IR (neat, $\left.\mathrm{cm}^{-1}\right): 3393(\mathrm{NH}), 1737(\mathrm{C}=\mathrm{O}), 1665(\mathrm{C}=\mathrm{O}), 1649$ $(\mathrm{C}=\mathrm{O})$.

\section{Methyl $N$-[3-acetylamino-2-(3-ethylcarbonyl-7-methoxy-naphthalen-1-yl)]-propionate}

(14b). This compound was prepared from $\mathbf{2 a}$ following procedure described for $\mathbf{1 4 a}$; Recrystallized from acetonitrile as a white solid (56\% yield); Mp 174-176 ${ }^{\circ} \mathrm{C}$; MS (APCI, pos. $30 \mathrm{~V}) \mathrm{m} / z:[\mathrm{M}+\mathrm{H}]^{+}, 358.18 ;{ }^{1} \mathrm{H}$ NMR (DMSO- $\left.d_{6}\right): \delta 1.10-1.15(\mathrm{~m}, 3 \mathrm{H}), 1.81(\mathrm{~s}, 3 \mathrm{H})$, 3.11-3.14 (m, 2H), 3.50-3.55 (m, 2H), 3.69 (s, 3H), 4.00 (s, 3H), $4.72(\mathrm{~m}, 1 \mathrm{H}), 7.31$ (dd, 1H, $J$ 
$=9.0, J=2.4), 7.79(\mathrm{~d}, 1 \mathrm{H}, J=2.0), 7.81(\mathrm{~d}, 1 \mathrm{H}, J=2.4), 8.08(\mathrm{~d}, 1 \mathrm{H}, J=9.0), 8.31$ (br s, $1 \mathrm{H}), 8.59(\mathrm{~d}, 1 \mathrm{H}, J=2.0)$; IR (neat, $\left.\mathrm{cm}^{-1}\right): 3365(\mathrm{NH}), 1734(\mathrm{C}=\mathrm{O}), 1663(\mathrm{C}=\mathrm{O}), 1649(\mathrm{C}=\mathrm{O})$.

Methyl $N$-[3-acetylamino-2-(3-ethyl-7-methoxy-naphthalen-1-yl)]propionate (15a).

To a solution of 14a $(2.0 \mathrm{~g}, 5.8 \mathrm{mmol})$ in $20 \mathrm{~mL}$ of trifluoroacetic acid (TFA) was added dropwise triethylsilane $(2.4 \mathrm{~mL}, 15.0 \mathrm{mmol})$ and the mixture was stirred at room temperature for $12 \mathrm{~h}$. The solvent was evaporated under reduced pressure and the white solid obtained was recrystallized from cyclohexane (94\% yield); Mp 68-70 ${ }^{\circ} \mathrm{C}$; MS (APCI, pos. $30 \mathrm{~V}) \mathrm{m} / z:[\mathrm{M}+\mathrm{H}]^{+}, 330.18 ;{ }^{1} \mathrm{H}$ NMR (DMSO- $\left.d_{6}\right): \delta 1.20-1.26(\mathrm{~m}, 3 \mathrm{H}), 1.81$ (s, 3H), 2.68-2.73 (m, 2H), 3.50-3.54 (m, 2H), $3.66(\mathrm{~s}, 3 \mathrm{H}), 3.94(\mathrm{~s}, 3 \mathrm{H}), 4.65(\mathrm{~m}, 1 \mathrm{H})$, $7.13(\mathrm{~d}, 1 \mathrm{H}, J=2.0), 7.16(\mathrm{dd}, 1 \mathrm{H}, J=9.0, J=2.4), 7.58(\mathrm{~d}, 1 \mathrm{H}, J=2.0), 7.70(\mathrm{~d}, 1 \mathrm{H}, J=$ 2.4), $7.79(\mathrm{~d}, 1 \mathrm{H}, J=9.0), 8.26$ (br s, 1H); IR (neat, $\left.\mathrm{cm}^{-1}\right)$ : $3390(\mathrm{NH}), 1743(\mathrm{C}=\mathrm{O}), 1630$ $(\mathrm{C}=\mathrm{O})$.

Methyl $N$-[3-acetylamino-2-(3-propyl-7-methoxy-naphthalen-1-yl)]propionate (15b). Prepared from 14b according to the procedure described for compound 15a; Recrystallized from cyclohexane as a white solid (98\% yield); Mp 76-80 ${ }^{\circ} \mathrm{C}$; MS (APCI, pos. $30 \mathrm{~V}$ ) m/z: $[\mathrm{M}+\mathrm{H}]^{+}, 344.20 ;{ }^{1} \mathrm{H}$ NMR (DMSO-d $): \delta 0.89-0.96(\mathrm{~m}, 3 \mathrm{H}), 1.60-1.65(\mathrm{~m}, 2 \mathrm{H}), 1.81(\mathrm{~s}$, $3 \mathrm{H}), 2.63-2.68(\mathrm{~m}, 2 \mathrm{H}), 3.50-3.56(\mathrm{~m}, 2 \mathrm{H}), 3.66(\mathrm{~s}, 3 \mathrm{H}), 3.93(\mathrm{~s}, 3 \mathrm{H}), 4.65(\mathrm{~m}, 1 \mathrm{H}), 7.10$ $(\mathrm{d}, 1 \mathrm{H}, J=2.0), 7.16(\mathrm{dd}, 1 \mathrm{H}, J=9.0, J=2.4), 7.56(\mathrm{~d}, 1 \mathrm{H}, J=2.0), 7.70(\mathrm{~d}, 1 \mathrm{H}, J=2.4)$, $7.78(\mathrm{~d}, 1 \mathrm{H}, J=9.0), 8.24($ br s, $1 \mathrm{H})$; IR (neat, $\left.\mathrm{cm}^{-1}\right): 3393(\mathrm{NH}), 1742(\mathrm{C}=\mathrm{O}), 1632$ $(\mathrm{C}=\mathrm{O})$.

$N$-[3-Hydroxy-2-(3-ethyl-7-methoxy-naphthalen-1-yl)propyl]acetamide (16a). Compound 15a $(2.0 \mathrm{~g}, 6.1 \mathrm{mmol})$ was dissolved in dry THF $(200 \mathrm{~mL})$, stirred and cooled at $0{ }^{\circ} \mathrm{C}$. Aluminum lithium hydride $(0.5 \mathrm{~g}, 12.1 \mathrm{mmol})$ was then added portionwise cautiously and the mixture was allowed to stir at room temperature for $6 \mathrm{~h} .2 \mathrm{~mL}$ of water were added followed by the addition of $2 \mathrm{~mL}$ of a $\mathrm{NaOH}$ solution $(1 \mathrm{~N})$. The mixture was washed with water and 
the organic phase was dried over $\mathrm{MgSO}_{4}$ and evaporated under reduced pressure to give the desired product as a white solid; Recrystallized from toluene (44\% yield); Mp 120-122 ${ }^{\circ} \mathrm{C}$; MS (APCI, pos. $30 \mathrm{~V}) \mathrm{m} / z:[\mathrm{M}+\mathrm{H}]^{+}, 302.16 ;{ }^{1} \mathrm{H}$ NMR (DMSO-d $): \delta 1.22-1.26(\mathrm{~m}, 3 \mathrm{H}), 1.76$ (s, 3H), 2.70-2.73 (m, 2H), 3.39-3.42 (m, 2H), 3.73-3.76 (m, 3H), 3.91 (s, 3H), 4.71 (br s, 1H), $7.13(\mathrm{dd}, 1 \mathrm{H}, J=9.0, J=2.4), 7.31(\mathrm{~d}, 1 \mathrm{H}, J=2.0), 7.48(\mathrm{~d}, 1 \mathrm{H}, J=2.0), 7.54(\mathrm{~d}, 1 \mathrm{H}, J$ $=2.4), 7.74(\mathrm{~d}, 1 \mathrm{H}, J=9.0), 7.91(\mathrm{br} \mathrm{s}, 1 \mathrm{H}) ;{ }^{13} \mathrm{C}$ NMR (DMSO- $\left.d_{6}\right): \delta 15.9,23.1,28.8,41.6$, $42.3,55.7,63.2,102.8,118.1,124.5,126.0,129.6,130.2,132.3,136.7,138.7,157.3,170.1$; IR (neat, $\left.\mathrm{cm}^{-1}\right)$ : $3260(\mathrm{NH}), 2959-2852(\mathrm{OH}), 1634(\mathrm{C}=\mathrm{O})$; Anal. $\left(\mathrm{C}_{18} \mathrm{H}_{23} \mathrm{NO}_{3}\right) \mathrm{C}, \mathrm{H}, \mathrm{N}$.

$N$-[3-Hydroxy-2-(3-propyl-7-methoxy-naphthalen-1-yl)propyl]acetamide $\quad(16 \mathrm{~b}) . \quad$ This compound was prepared from 15b following procedure described for 16a; Recrystallized from acetonitrile as a white solid (42\% yield); Mp 142-144 ${ }^{\circ} \mathrm{C}$; MS (APCI, pos. $\left.30 \mathrm{~V}\right) \mathrm{m} / \mathrm{z}$ : $[\mathrm{M}+\mathrm{H}]^{+}, 316.19 ;{ }^{1} \mathrm{H}$ NMR (DMSO- $\left.d_{6}\right): \delta 0.89-0.93(\mathrm{~m}, 3 \mathrm{H}), 1.62-1.66(\mathrm{~m}, 2 \mathrm{H}), 1.75(\mathrm{~s}, 3 \mathrm{H})$, 2.61-2.63 (m, 2H), $3.33(\mathrm{~m}, 1 \mathrm{H}), 3.45(\mathrm{~m}, 1 \mathrm{H}), 3.72-3.74(\mathrm{~m}, 3 \mathrm{H}), 3.90(\mathrm{~s}, 3 \mathrm{H}), 4.71$ (br s, 1H), $7.11(\mathrm{dd}, 1 \mathrm{H}, J=9.0, J=2.4), 7.28(\mathrm{~d}, 1 \mathrm{H}, J=2.0), 7.46(\mathrm{~d}, 1 \mathrm{H}, J=2.0), 7.54(\mathrm{~d}, 1 \mathrm{H}, J$ $=2.4), 7.73(\mathrm{~d}, 1 \mathrm{H}, J=9.0), 7.90($ br s, $1 \mathrm{H}) ;{ }^{13} \mathrm{C}$ NMR $\left(\mathrm{DMSO}-d_{6}\right): \delta 10.5,16.0,23.3,28.9$, $41.9,42.5,55.6,63.1,102.6,118.2,124.0,125.9,129.2,130.0,132.3,136.7,138.3,157.3$, 170.0; IR (neat, $\left.\mathrm{cm}^{-1}\right)$ : $3258(\mathrm{NH}), 2959-2849(\mathrm{OH}), 1633(\mathrm{C}=\mathrm{O})$; Anal. $\left(\mathrm{C}_{19} \mathrm{H}_{25} \mathrm{NO}_{3}\right) \mathrm{C}, \mathrm{H}, \mathrm{N}$. Pharmacology: Reagents and chemicals. 2-[ $\left.{ }^{125} \mathrm{I}\right]$ Iodomelatonin $(2200 \mathrm{Ci} / \mathrm{mmol})$ was purchased from NEN (Boston, MA). Other drugs and chemicals were purchased from SigmaAldrich (Saint Quentin, France) and used without further purification.

Assays for $M T_{1}$ and $M T_{2}$ receptor subtypes. 2-[ $\left.{ }^{125} \mathrm{I}\right]$ Iodomelatonin competition binding assay conditions were essentially as previously described [31]. Briefly, binding was initiated by addition of membrane preparations from transfected $\mathrm{CHO}$ cells stably expressing the human melatonin $\mathrm{MT}_{1}$ or $\mathrm{MT}_{2}$ diluted in binding buffer $(50 \mathrm{mM}$ Tris- $\mathrm{HCl}$ buffer, $\mathrm{pH} 7.4$, containing $5 \mathrm{mM} \mathrm{MgCl}_{2}$ ) to 2-[ $\left.{ }^{125} \mathrm{I}\right]$ iodomelatonin (20 $\mathrm{pM}$ for $\mathrm{MT}_{1}$ and $\mathrm{MT}_{2}$ receptors expressed in $\mathrm{CHO}$ 
cells) and the tested drug. Non-specific binding was defined in the presence of $1 \mu \mathrm{M}$ of melatonin. After 120 min incubation at $37^{\circ} \mathrm{C}$, reaction was stopped by rapid filtration through GF/B filters presoaked in $0.5 \%(\mathrm{v} / \mathrm{v})$ polyethylenimine. Filters were washed three times with $1 \mathrm{~mL}$ of ice-cold $50 \mathrm{mM}$ Tris-HCl buffer ( $\mathrm{pH} 7.4)$.

Data from the dose-response curves (seven concentrations in duplicate) were analysed using the program PRISM (Graph Pad Software Inc., San Diego, CA) to yield IC $_{50}$ (inhibitory concentration 50). Affinities are expressed as $\mathrm{pKi}(\mathrm{pKi}=-\log 10(\mathrm{Ki}))$ with $\mathrm{Ki}=\mathrm{IC}_{50} / 1+$ $([\mathrm{L}] / \mathrm{KD})$, where $[\mathrm{L}]$ is the concentration of radioligand used in the assay and $\mathrm{KD}$, the dissociation constant of the radioligand characterizing the membrane preparation.

$\left[{ }^{35} \mathrm{~S}\right] \mathrm{GTP} \gamma \mathrm{S}$ binding assay was performed according to published methodology [31]. Briefly, membranes from transfected $\mathrm{CHO}$ cells expressing $\mathrm{MT}_{1}$ and $\mathrm{MT}_{2}$ receptor subtypes and compounds were diluted in binding buffer (20 mM HEPES, pH 7.4, $100 \mathrm{mM} \mathrm{NaCl}, 3 \mu \mathrm{M}$ GDP, $3 \mathrm{mM} \mathrm{MgCl} 2$, and $20 \mu \mathrm{g} / \mathrm{mL}$ saponin). Incubation was started by the addition of $0.2 \mathrm{nM}$ $\left[{ }^{35} \mathrm{~S}\right] \mathrm{GTP} \gamma \mathrm{S}$ to membranes $(20 \mu \mathrm{g} / \mathrm{mL})$ and drugs, and further followed for $1 \mathrm{~h}$ at room temperature. Reaction was stopped by rapid filtration through GF/B filters followed by three successive washes with ice-cold buffer.

Usual levels of $\left[{ }^{35} \mathrm{~S}\right] \mathrm{GTP} \gamma \mathrm{S}$ binding (expressed in dpm) were for $\mathrm{CHO}^{-\mathrm{MT}_{2}}$ membranes: 2000 for basal activity, 8000 in the presence of melatonin $1 \mu \mathrm{M}$ and 180 in the presence of GTP $\gamma \mathrm{S}$ $10 \mu \mathrm{M}$ which defined the non-specific binding. Data from the dose-response curves (seven concentrations in duplicate) were analyzed by using the program PRISM (Graph Pad Software Inc., San Diego, CA) to yield pEC $50\left(p E C 50=-\log _{10}\left(E_{50}\right)\right.$ with $\mathrm{EC}_{50}$ the effective concentration 50\%) and Emax (maximal effect) for agonists.

Assays for 5-HT $2 \mathrm{C}$ receptor subtypes. Serotonin 5-HT $2 \mathrm{C}$ competition binding assay was determined according to the protocol previously reported in the literature [32]. Membranes from $\mathrm{CHO}$ cell lines, stably expressing the human $5-\mathrm{HT}_{2} \mathrm{C}(\mathrm{VSV})$ receptors were incubated for 
$60 \mathrm{~min}$ at $37{ }^{\circ} \mathrm{C}$ in binding buffer $(50 \mathrm{mM}$ Tris- $\mathrm{HCl}$ buffer $(\mathrm{pH} 7.4)$, containing $10 \mathrm{mM}$ $\mathrm{MgCl}_{2}$ and $0.1 \%$ BSA) containing the radioligand $\left[{ }^{3} \mathrm{H}\right]$ mesulergine $(1 \mathrm{nM})$. Non-specific binding was defined in the presence of $10 \mu \mathrm{M}$ mianserine. Reaction was terminated by rapid filtration through GF/B filters presoaked in $0.1 \%(\mathrm{v} / \mathrm{v})$ polyethylenimine. Filters were washed three times with $1 \mathrm{~mL}$ of ice-cold $50 \mathrm{mM}$ Tris- $\mathrm{HCl}$ buffer (pH 7.4). Residual radioactivity on filters was measured using a TopCount scintillation counter (PerkinElmer Life Sciences) after addition of Microscint 20. Isotherms were analyzed using non-linear regression to yield $\mathrm{IC}_{50}$. Affinities are expressed as Ki.

\section{Acknowledgement}

The authors would like to gratefully acknowledge the Region Nord Pas de Calais (France), the Ministère de la Jeunesse, de l'Education Nationale et de la Recherche (MJENR) and the Fonds Européens de Développement Régional (FEDER) for funds allowed for the 300 MHz NMR facilities.

\section{References}

[1] Reiter, R.J. Endocr. Rev. 1991, 12, 151-180.

[2] (a) Reppert, S.M.; Weaver, D.R.; Godson, C. Trends Pharmacol. Sci. 1996, 17, 100-102; (b) Von Gall, C.; Stehle, J.H.; Weaver, D.R. Cell Tissue Res. 2002, 309, 151-162; (c) Dubocovich, M.L.; Delagrange, P.; Krause, D.N.; Sugden, D.; Cardinali, D.P.; Olcese, J. Pharmacol. Rev. 2010, 62, 343-380.

[3] Dubocovich, M.L.; Markowska, M. Endocrine 2005, 27, 101-110.

[4] Wu, Y.H.; Zhou, J.N.; Balesar, R.; Unmehopa, U.; Bao, A.; Jockers, R.; van Heerikhuize, J.; Swaab, D.F. J. Comp. Neurol. 2006, 499, 897-910. 
[5] Nosjean, O.; Ferro, M.; Coge, F.; Beauverger, P.; Henlin, J.M.; Lefoulon, F.; Fauchere, J.L.; Delagrange, P.; Canet, E.; Boutin, J.A. J. Biol. Chem. 2000, 275, 31311-31317.

[6] Arendt, J. J Biol. Rhythms 2005, 20, 291-303.

[7] Pandi-Perumal, S.R.; Trakht, I.; Srinivasan, V.; Spence, D.W.; Maestroni, G.J.M.; Zisapel, N.; Cardinali, D.P. Prog. Neurobiol. 2008, 85, 335-353.

[8] Pandi-Perumal, S.R.; Srinivasan, V.; Maestroni, G.J.M.; Cardinali, D.P.; Poeggeler, B.; Hardeland, R. FEBS J. 2006, 273, 2813-2838.

[9] Lerner, A.B.; Case, J.D.; Heinzelman, R.V. J. Am. Chem. Soc. 1959, 81, 6084-6085.

[10] Pévet, P.; Bothorel, B.; Slotten, H.; Saboureau, M. Cell Tissue Res. 2002, 309, 183-191.

[11] Lyssenko, V.; Nagorny, C.L.F.; Erdos, M.R.; Wierup, N.; Jonsson, A.; Spégel, P.; Bugliani, M.; Saxena, R.; Fex, M.; Pulizzi, N.; Isomaa, B.; Tuomi, T.; Nilsson, P.; Kuusisto, J.; Tuomilehto, J.; Boehnke, M.; Altshuler, D.; Sundler, F.; Eriksson, J.G.; Jackson, A.U.; Laakso, M.; Marchetti, P.; Watanabe, R.M.; Mulder, H.; Groop, L.; Nat. Genet. 2009, 41, 82-88.

[12] (a) Srinivasan, V.; Smits, M.; Spence, W.; Lowe, A.D.; Kayumov, L.; Pandi-Perumal, S.R.; Parry, B.; Cardinali, D.P. World J. Biol. Psychiatry 2006, 7, 138-151; (b) Lanfumey, L.; Mongeau, R.; Hamon, M. Pharmacol. Ther. 2013, 138, 176-184.

[13] Soria, V.; Urretavizcaya, M. Actas Esp. Psiquiatr. 2009, 37, 222-232.

[14] Turek, F.W. Int. Clin. Psychopharmacol. 2007, 22 (Suppl. 2), S1-S8.

[15] (a) Radogna, F.; Paternoster, L.; Albertini, M.C.; Cerella, C.; Accorsi, A.; Bucchini, A.; Spadoni, G.; Diamantini, G.; Tarzia, G.; De Nicola, M.; D’Alessio, M.; Ghibelli, L.J. Pineal Res. 2007, 43, 154-162; (b) García-Navarro, A.; González-Puga, C.; Escames, G.; López, L.C.; López, A.; López-Cantarero, M.; Camacho, E.; Espinosa, A.; Gallo, M.A.; Acuña-Castroviejo, D. J. Pineal Res. 2007, 43, 195-205.

[16] Wang, J-Z.; Wang, Z-F. Acta Pharmacol. Sinica 2006, 27, 41-49. 
[17] Srinivasan, V.; Pandi-Perumal, S.R.; Cardinali, D.P.; Poeggeler, B.; Hardeland, R. Behav. Brain Funct. 2006, 2, 15.

[18] (a) F. W. Turek, Int. Clin. Psychorpharmacol. 2007, 22, S1 -S8; (b) De Berardis, D.; Marini, S.; Fornaro, M.; Srinivasan, V.; Iasevoli, F.; Tomasetti, C.; Valchera, A.; Perna, G.; Quera-Salva, M.A.; Martinotti, G.; di Giannantonio, M. Int. J. Mol. Sci. 2013, 14, $12458-12483$.

[19] Kennedy, S.H.; Emsley, R. Eur. Neuropsychopharmacol. 2006, 16, 93-100.

[20] Miyamoto, M. CNS Neurosci. Ther. 2009, 15, 32-51.

[21] Vachharajani, N.N.; Yeleswaram, K.; Boulton, D.W. J. Pharm. Sci. 2003, 92, 760-772.

[22] (a) Nickelsen, C.; Samel, A.; Vejvoda, M.; Wenzel, J.; Smith, B.; Gerzer, R. Chronobiol. Int. 2002, 19, 915-936; (b) Flaugh, M.E.; Bruns, R.F.; Shipley, L.A.; Clemens, J.A. Lilly Research Laboratories, Eli Lilly Company, Indianapolis, IN, USA. Webb, S.M., Ed.; 7th Colloquium of the European Pineal Society, Sitges, Spain, March 29-31, 1996; pp $321-330$.

[23] Ettaoussi, M.; Sabaouni, A.; Rami, M.; Boutin, J.A.; Delagrange, P.; Renard, P.; Spedding, M.; Caignard, D.H.; Berthelot, P.; Yous, S. Eur. J. Med. Chem. 2012, 49, 310-323.

[24] (a) Ettaoussi, M.; Sabaouni, A.; Pérès, B.; Landagaray, E.; Nosjean, O.; Boutin, J.A.; Caignard, D.H.; Delagrange, P.; Berthelot, P.; Yous, S. ChemMedChem. 2013, 8, 18301845; (b) Ettaoussi, M.; Pérès, B.; Jarry, C.; Pallage, V.; Nosjean, O.; Boutin, J.A.; Gohier, A.; Mannoury la Cour, C.; Caignard, D.H.; Delagrange, P.; Berthelot, P.; Yous, S. MedChemComm. 2014, 5, 1303-1308.

[25] Yous, S.; Depreux, P.; Renard, P. Arch. Pharm. 1993, 326, 119-120.

[26] Swan, G.A. J. Chem. Soc. Perkin Trans. II 1949, 2, 169-173.

[27] Stille, J.K. Angew. Chem. Inter. Edition in English 1986, 25, 508. 
[28] West, C.T.; Donnelly, S.J.; Kooistra, D.A.; Doyle, M.P. J. Org. Chem. 1973, 38, 26752681.

[29] Pedras, M.S.C.; Jha, M. Bioorg. Med. Chem. 2006, 14, 4958-4979.

[30] Amemiya, Y.; Hong, S.S.; Venkataraman, B.V.; Patil, P.N.; Shams, G.; Romstedt, K.; Feller, D.R.; Hsu, F.L.; Miller, D.D. J. Med. Chem. 1992, 35, 750-755.

[31] Audinot, V.; Mailliet, F.; Lahaye-Brasseur, C.; Bonnaud, A.; Le Gall, A.; Amossé, C.; Dromaint, S.; Rodriguez, M.; Nagel, N.; Galizzi J.P.; Malpaux, B.; Guillaumet, G.; Lesieur, D.; Lefoulon, F.; Renard, P.; Delagrange, P.; Boutin, J.A. Naunyn-Schmiedeberg's Arch. Pharmacol. 2003, 367, 553-561.

[32] Holst, B.; Nygaard, R.; Valentin-Hansen, L.; Bach, A.; Engelstoft, M.S.; Petersen, P.S.; Frimurer, T.M.; Schwartz, T.W. J. Biol. Chem. 2011, 285, 3973. 